Aus der Abteilung Rechtsmedizin

(Ehem. Leiter: Prof. Dr. med. Michael Klintschar)

im Zentrum Pathologie und Rechtsmedizin

der Medizinischen Fakultät der Universität Göttingen

\title{
Untersuchung zur differentiellen Expression von Serotonin-2B-Rezeptoren im Hirnstamm bei Plötzlichem Kindstod
}

\author{
INAUGURAL-DISSERTATION \\ Zur Erlangung des Doktorgrades \\ der Medizinischen Fakultät \\ der Georg-August-Universität zu Göttingen
}

\author{
Vorgelegt von \\ Antonia Scheiblich \\ aus \\ Hannover
}

Göttingen 2011 
Dekan: Prof. Dr. med. C. Frömmel

I. Berichterstatter: Prof. Dr. med. M. Klintschar

II. Berichterstatter: Prof. Dr. rer. nat. M. Müller

Tag der mündlichen Prüfung: 20.09.2011 


\section{Verzeichnis der verwendeten Abkürzungen}

$a b$

Abb.

AC

BSA

CpG

$\mathrm{CrKO}_{8} \mathrm{~S}_{2}{ }^{*} 12 \mathrm{H}_{2} \mathrm{O}$

$\mathrm{Cu}$

DAB

$\mathrm{ddH}_{2} \mathrm{O}$

f

Fig.

FoxP2

GFAP

gi

Gln

$\mathrm{Gr}$

$\mathrm{H}_{2} \mathrm{O}_{2}$

5-HT

Hy

Icp

IOam

IOap
Nucleus abducens

Abbildung

Adenylatzyklase

Bovines Serumalbumin

Cytosin und Guanin verbunden durch Phosphodiesterbindung

Chrom(III)-kaliumsulfat-Dodecahydrat

Nucleus cuneatus

Diaminobenzidin

doppelt destilliertes Wasser

folgende

figure $=$ Abbildung

Forkhead-Box-Protein P2

Glial fibrillary acidic protein

Nucleus gigantocellularis

Glyzin

Nucleus gracilis

Wasserstoffperoxid

5-Hydroxytryptamin $=$ Serotonin

Nucleus hypoglossus

Pedunculus cerebellaris inferior

Nucleus olivaris accessorius medius

Nucleus olivaris accessorius posterior 


\begin{tabular}{|c|c|}
\hline IOpr & Nucleus olivaris principalis \\
\hline Irt & intermediäre Zone der Formatio reticularis \\
\hline$\mu l$ & Mikroliter \\
\hline$\mu \mathrm{m}$ & Mikrometer \\
\hline M & Mittelwert \\
\hline $\mathrm{m}$ & Monate alt \\
\hline MBP & Myelin-Basisches-Protein \\
\hline MeCP2 & methyl $\mathrm{CpG}$ binding protein 2 \\
\hline$n$ & Fallzahl \\
\hline $\mathrm{NaCl}$ & Natriumchlorid \\
\hline NMDA & N-Methyl-D-Aspartat \\
\hline Nspnt & Nucleus spinalis nervi trigemini \\
\hline PBS & englisch: Phosphate Buffered Saline \\
\hline PLC & Phospholipase C \\
\hline Py & Tractus pyramidalis \\
\hline Rob & Nucleus raphe obscurus \\
\hline SEM & Standardfehler \\
\hline Ser & Serin \\
\hline SIDS & Suddent Infant Death Syndrome $=$ Plötzlicher Kindstod \\
\hline SIDS IA & $\begin{array}{l}\text { untersuchte Gruppe aller Fälle Plötzlichen Kindstodes ohne } \\
\text { Auffälligkeiten bei der Obduktion }\end{array}$ \\
\hline SIDS ॥ & $\begin{array}{l}\text { untersuchte Gruppe aller Fälle Plötzlichen Kindstodes mit } \\
\text { Zeichen einer milden Entzündung }\end{array}$ \\
\hline tiff & englisch: tagged image file format \\
\hline
\end{tabular}


$4 \mathrm{~V}$

ZNS vierter Ventrikel

Zentrales Nervensystem

Aminosäureabkürzungen (englisch: single letter code):

$\begin{array}{llllllll}\text { A } & \text { Alanin } & \text { Q } & \text { Glutamin } & \text { L } & \text { Leuzin } & \text { S } & \text { Serin } \\ \text { R } & \text { Arginin } & \text { E } & \text { Glutamat } & \text { K } & \text { Lysin } & \text { T } & \text { Threonin } \\ \text { N } & \text { Asparagin } & \text { G } & \text { Glyzin } & \text { M } & \text { Methionin } & \text { W } & \text { Tryptophan } \\ \text { D } & \text { Aspartat } & \text { H } & \text { Histidin } & \text { F } & \text { Phenylalanin } & \text { Y } & \text { Tyrosin } \\ \text { C } & \text { Cystein } & \text { I } & \text { Isoleuzin } & \text { P } & \text { Prolin } & \text { V } & \text { Valin }\end{array}$




\section{Inhaltsverzeichnis}

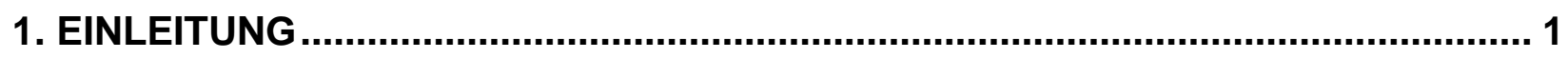

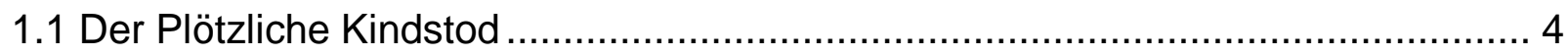

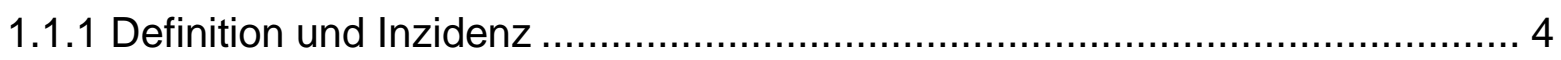

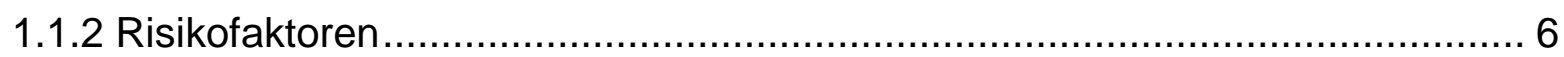

1.1.3 Die Theorie des Fatalen Dreiecks - englisch: Triple Risk Model.................... 7

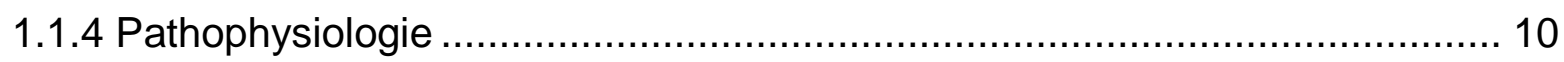

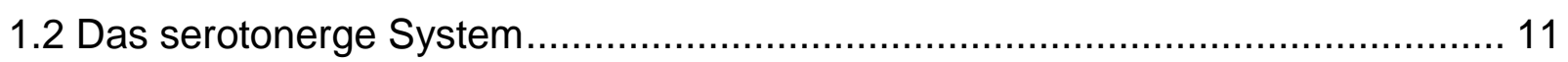

1.2.1 Serotonin und Serotoninsynthese ....................................................... 11

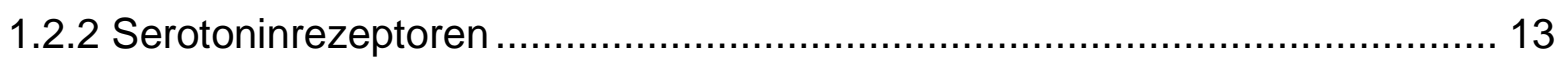

1.2.3 Verteilung und Funktion der 5-HT2B-Rezeptoren .................................... 15

1.2.4 Das Serotonerge System und seine Bedeutung für den

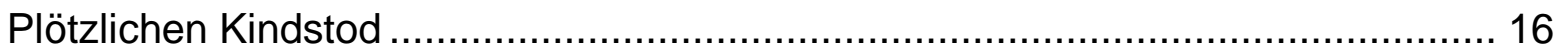

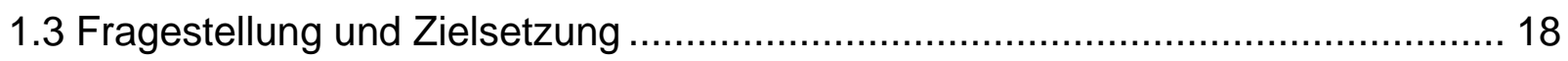

2. MATERIAL UND METHODEN

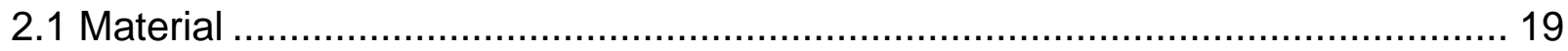

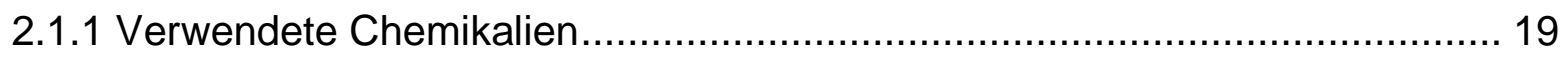

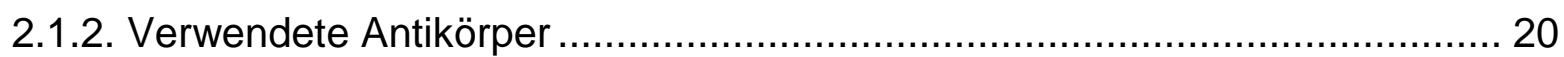

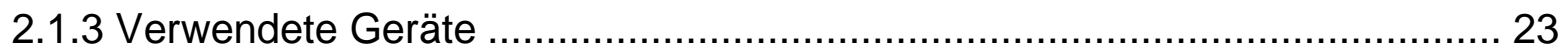

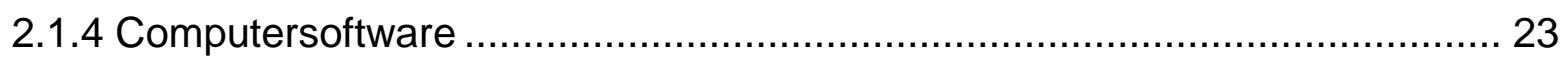

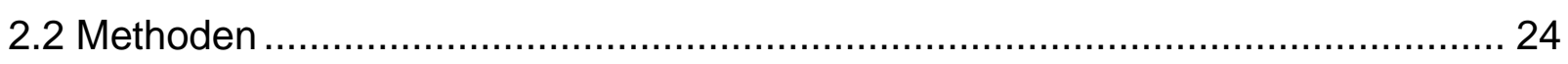

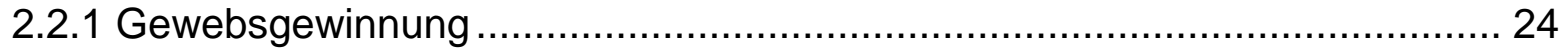

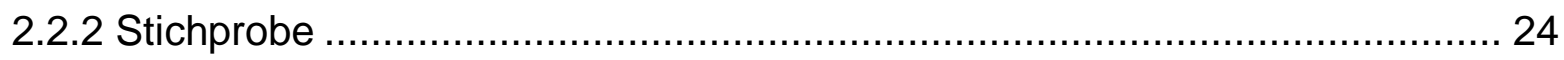

2.2.3 Erzeugung frei schwimmender Gefrierschnitte ....................................... 26

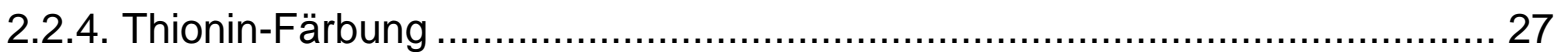

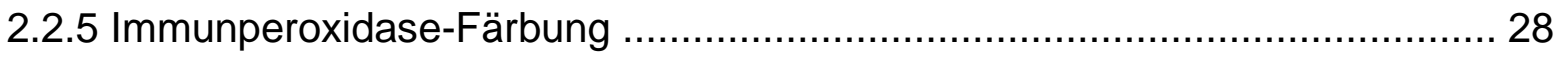

2.2.6 Peroxidasereaktion in Diaminobenzidin-Lösung (DAB) .............................. 29

2.2.7 Eindecken der Schnitte in permanente Eindeckmedien ............................. 30

2.2.8 Gelatinieren der Objektträger ............................................................... 31 
2.2.9 Analyse der Zelldichte mit dem Coolescope und digitale Bildverarbeitung.... 32

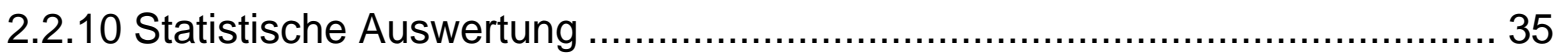

3 ERGEBNISSE

3.1 Die Topographie der 5-HT2B-Rezeptoren in der Medulla oblongata ................... 37

3.2 Analyse der Zellzahl und Zelldichte mit Hilfe des Coolscopes ............................ 43

3.2.1 Fälle Plötzlichen Kindstodes (SIDS IA) im Vergleich mit der Kontrollgruppe . 43

3.2.2 Fälle Plötzlichen Kindstodes mit entzündlicher Komponente (SIDS II) im

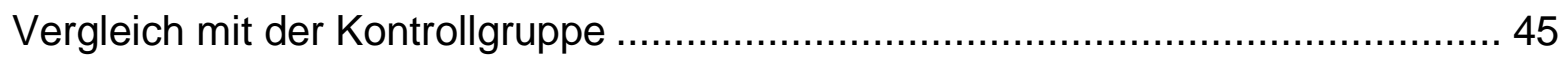

3.2.3 Fälle Plötzlichen Kindstodes (SIDS IA + SIDS II) im Vergleich mit der

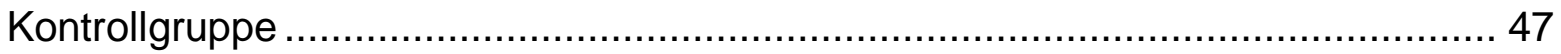

3.3 Graphische Zusammenfassung der Resultate ............................................. 49

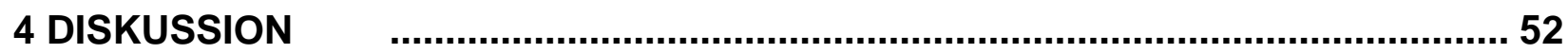

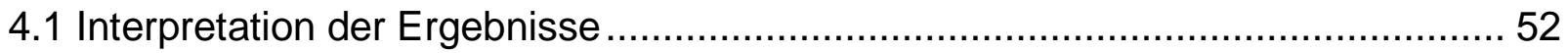

4.2 Vergleich mit anderen Autoren: Serotonin und respiratorische Disregulation ...... 54

4.3 Hirnstammpathologien in anderen Neurotransmittersystemen ......................... 56

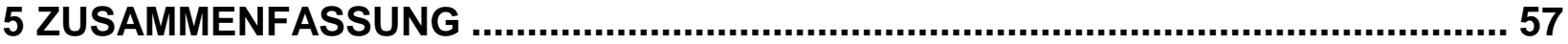

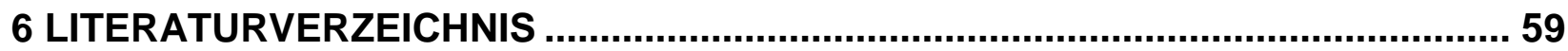




\section{Einleitung}

Der Plötzliche Kindstod ist ein uraltes Thema der Menschheit, denn er wurde bereits in der Antike in der Bibel thematisiert. Wie schon in Salomos Urteil (Bibel: 1. Könige 3; 1628) nachzulesen ist, starb der Säugling einer Hure unerwartet während der Nacht. Daraufhin tauschte sie das tote Kind gegen das lebende ihrer Bettnachbarin aus. Am nächsten Morgen kam es zum Streit um den noch lebenden Säugling zwischen den beiden Müttern, die sich gegenseitig vorwarfen, ihr eigenes Kind im Schlaf erdrückt zu haben. Durch König Salomos Geschick gelang es dennoch, die richtige Mutter zu ermitteln, die Todesursache blieb jedoch ungeklärt. Für viele Jahrhunderte blieb so das versehentliche Erdrücken im Schlaf wohl die einzige Erklärungsmöglichkeit.

Plötzlich, unerwartet und unerklärbar sterben noch heute in Deutschland jährlich 228 Säuglinge an Plötzlichem Kindstod, darunter 138 Jungen und 90 Mädchen (Statistisches Bundesamt, 2008).

Damit ist der Plötzliche Kindstod mit 25\% die häufigste Todesursache im Säuglingsalter zwischen 1 Monat und 1 Jahr (Hunt und Hauck 2006).

Qua definitionem ist der Plötzliche Kindstod: „....the sudden death of an infant under one year of age, which remains unexplained after a thorough case investigation, including performance of a complete autopsy, examination of the death scene, and review of the clinical history" (Willinger et al. 1991, S.677). Die Definition des Plötzlichen Kindstodes (englisch: Sudden Infant Death Syndrome, SIDS) kann also folgendermaßen übersetzt werden: Der Plötzliche Kindstod beschreibt den plötzlichen, unerwarteten Tod eines Säuglings unter einem Jahr, ohne dass sich in der Vorgeschichte, der Auffindesituation 
oder bei der Autopsie eine ausreichende todeserklärende Ursache finden lässt. Der Plötzliche Kindstod tritt in der Regel im Schlaf auf; dabei spielt es keine Rolle, ob der Säugling zum Nacht- oder Mittagsschlaf hingelegt wurde (Kinney et al. 2009b).

Betroffen sind Säuglinge innerhalb des ersten Lebensjahres, mit einem Häufigkeitsgipfel zwischen dem 2. und 4. Lebensmonat. Die Säuglingssterblichkeit bei Jungen ist vor allem in den ersten vier Lebenswochen deutlich höher (Hunt und Hauck 2006). Der pathophysiologische Mechanismus ist bislang ungeklärt.

Zahlreiche Studien finden keine spezifische Ursache für dieses Phänomen, die gegenwärtig am häufigsten akzeptierte Arbeitshypothese geht von der Prämisse aus, dass es sich beim Plötzlichen Kindstod um ein multifaktorielles Syndrom handelt (Filiano und Kinney 1994; Guntheroth und Spiers 2002; Vege und Rognum 2004).

Neben zahlreichen epidemiologischen Risikofaktoren gewinnen genetische Faktoren sowohl für Forschungskonzepte als auch für Präventionsmaßnahmen zunehmend an Interesse. Der Zusammenhang zwischen epidemiologischen und genetischen Risikofaktoren könnte zukünftig in der Abschätzung des individuellen SIDS-Risikos eines Kindes an Bedeutung gewinnen (Kinney et al. 2009a).

Die Erarbeitung geeigneter präventiver Maßnahmen beruht also auf der Erfassung von epidemiologischen und genetischen Risikofaktoren. Somit ist zur Zeit die Erfassung von Risikofaktoren die Herausforderung bei der Bekämpfung des Plötzlichen Kindstodes. Um dieser Herausforderung gerecht zu werden, ist die interdisziplinäre Zusammenarbeit der Mutter und Kind betreuenden Fächer und der Grundlagenforschung conditio sine qua non.

Bisher deuten einige Veröffentlichungen auf Pathologien im Zentralen Nervensystem hin, die möglicherweise das Risiko, die zu Grunde liegende Vulnerabilität, für den 
Plötzlichen Kindstod erhöhen (Klintschar et al. 2008; Lavezzi et al. 2009; Machaalani et al. 2009; Narita et al. 2001; Paterson et al. 2006; Weese-Mayer et al. 2003, 2007) Es wurden Polymorphismen im Serotonin-Transporter-Gen gefunden, die in Verbindung mit dem Plötzlichen Kindstod stehen (Narita et al. 2001). Immunhistochemisch konnte ein verminderter $5-\mathrm{HT}_{1 \mathrm{~A}}$-Rezeptorbesatz mit dem Plötzlichen Kindstod assoziiert werden (Machaalani et al. 2009). Serotoninerge Neurone regulieren Funktionen des autonomen Nervensystems, wie zum Beispiel die Atemregulation und die Arousal Reaktion bei Hypoxie. Das Versagen dieser Kontrollmechanismen führt letztendlich zum Plötzlichen Kindstod.

Serotoninerge Neurone modulieren die Aktivität des respiratorischen Netzwerks im Hirnstamm und kontrollieren damit sowohl die Atemfrequenz als auch die Amplitude (Kubin und Volgin 2008; Lalley et al. 1994; Manzke et al. 2005a,b; Richter et al. 1997). Durch die Kontrolle der Atmung kommt dem serotonergen System möglicherweise eine Schlüsselrolle in der Pathologie des Plötzlichen Kindstods zu.

Erste Aufschlüsse über die funktionelle Bedeutung des $5-\mathrm{HT}_{2 \mathrm{~B}}-$ Rezeptors gibt eine tierexperimentelle Studie, die dem $5-\mathrm{HT}_{2 \mathrm{~B}}$-Rezeptor eine exzitatorische Funktion im PräBötzinger-Komplex, dem Atemrhythmusgenerator, zuschreibt. Stimulation des $5-\mathrm{HT}_{2 \mathrm{~B}^{-}}$ Rezeptors führt zu einer erhöhten morotischen Aktiviät des Nervus phrenicus und damit zu einer Atemfrequenzsteigerung (Manzke et al. 2005a,b).

Bisher ist die Verteilung des $5-\mathrm{HT}_{2 \mathrm{~B}}$-Rezeptors nur im Tiermodell analysiert worden. Die Expression des 5- $\mathrm{HT}_{2 \mathrm{~B}}$-Rezeptors ist für den Neokortex, das Kleinhirn, den dorsalen Hypothalamus und die mediale Amygdala der Ratte beschrieben (Duxon et al. 1997). Die Expression des $5-\mathrm{HT}_{2 \mathrm{~B}}$-Rezeptors im Hirnstamm der Ratte ist erst seit kurzem bekannt (Manzke et al. 2005a,b). 
Diese Arbeit untersucht die bisher unbekannte Expression des $5-\mathrm{HT}_{2 \mathrm{~B}}$-Rezeptors in der humanen Medulla oblongata und seine Bedeutung für den Plötzlichen Kindstod. Über die neuroanatomischen Fakten hinaus soll diese Arbeit dazu beitragen, ein detaillierteres Verständnis des serotonergen Systems zu ermöglichen.

\subsection{Der Plötzliche Kindstod}

\subsubsection{Definition und Inzidenz}

Trotz zahlreicher Definitionsversuche bleibt die Diagnose des Plötzlichen Kindstodes bis heute eine Ausschlussdiagnose. 1969 wurde erstmalig auf der National Institute of Health Consensus Conference versucht, dieses Syndrom exakt zu beschreiben. Der Plötzliche Kindstod sei der Tod eines Säuglings oder Kleinkindes, das unerwartet stirbt und dessen Tod durch eine Autopsie nicht erklärt werden kann (Beckwith 1970). Später wurde diese Definition erweitert, damit beschränkt sich die Diagnose des Plötzlichen Kindstodes nur noch auf Kinder, im Alter unter 12 Monaten, deren Tod im Schlaf auftrit und der auch nicht durch die Auffindesituation erklärt werden kann (Willinger et al. 1991).

Obwohl es keine pathognomonischen Auffälligkeiten bei der Autopsie eines an SIDS verstorbenen Säuglings gibt, findet man gehäuft Petechien des Thymus, der viszeralen Pleura und des Epikards. In einigen Fällen ist die Lunge gestaut und es liegt ein Lungenödem vor (Hunt und Hauck 2006).

Das Syndrom des Plötzlichen Kindtodes ist noch weitgehend unverstanden und macht daher eine internationale einheitliche Klassifikation unmöglich. Daher ergeben sich 
widersprüchliche Studienergebnisse allein schon auf Grund der Problematik bei der Klassifikation der einzelnen Fälle und ihrer Zuordnung in die zu untersuchenden Gruppen.

In den letzten Jahren wurden zum Beispiel einige dem Plötzlichen Kindstod zugeordneten Fälle aufgedeckt, deren Tod auf Grund von Mutationen im Acyl-CoenzymA-Dehydrogenase (MCAD)-Gen (Opdal and Rognum 2004) oder durch genetische kardiale Kannalopathien (Arnestad et al. 2007) verursacht wurde.

Obwohl nach Aufklärungskampagnen über Risikofaktoren für den Plötzlichen Kindstod, wie etwa das Schlafen auf dem Bauch, die Inzidenz des Plötzlichen Kindstodes zurückgedrängt werden konnte, bleibt der Plötzliche Kindstod noch immer die führende Todesursache von Säuglingen in Industrieländern nach Vollendung der ersten Lebenswoche. Etwa 90\% der Plötzlichen Kindstode ereignen sich in den ersten 6 Lebensmonaten mit einem Häufigkeitsgipfel zwischen 2 und 4 Lebensmonaten. Jungen sind häufiger betroffen als Mädchen, mit einer Ratio von 60:40 (Moon et al. 2007). Unter den Industrienationen führt Neuseeland mit der höchsten Rate von 0.8 Plötzlichen Kindstoden per 1000 Kindern die Statistik an, wohingegen in Japan mit 0.09 Plötzlichen Kindstoden pro 1000 Kindern die niedrigste Rate zu finden ist (Moon et al. 2007). 


\subsubsection{Risikofaktoren}

Besondere Bedeutung kommt den Risikofaktoren der Bauchlage, Überwärmung und dem Rauchen zu. Aber auch demographische und soziale Faktoren bestimmen das Risiko des Plötzlichen Kindstodes. So ist das Risiko für den Plötzlichen Kindstod von Kindern sehr junger Mütter (unter 18 Jahre), mit niedrigem sozioökonomischem Status, niedriger Schulbildung und kurzen Geburtsabständen deutlich erhöht. Auch in kinderreichen Familien mit mehr als drei Kindern und bei Arbeitslosigkeit des Vaters steigt das Risiko für den Plötzlichen Kindstod (Hunt und Hauck 2006).

Darüberhinaus beeinflussen mütterliche und antenatale Faktoren das Risiko für den Plötzlichen Kindstod. Untergewichtigkeit des Kindes bei der Geburt, mangelnde Kontrollen in der Schwangerschaft (weniger als fünf Vorsorgeuntersuchungen), Frühgeburtlichkeit, intrauterine Wachstumsretardierung und Hypoxie, Mehrlingsschwangerschaften, rezidivierende Infekte, Anämie, Drogenabhängigkeit, Opiateinnahme, frühes Abstillen (weniger als 2 Monate gestillt), perinatale Asphyxie des Kindes, Amnioninfektionssyndrom und abnorme neurologische Befunde in der Neonatalperiode erhöhen das Risiko ebenfalls (Hunt und Hauck 2006).

Das Benutzen eines „Schnullers“ hingegen senkt wiederum das Risiko für SIDS (Hauck et al. 2005).

Wenn ein Kind nicht nur in Bauchlage, sondern auch noch auf einer weichen Unterlage wie zum Beispiel einem Kissen oder Sofa liegt, erhöht sich das Risiko für den Plötzlichen Kindstod um den Faktor 20 (Kinney et al. 2009b). Dass Risikofaktoren, die mit Asphyxie verknüpft werden können, eine große Bedeutung haben, zeigt eine Studie, in der 85\% von 209 Fällen Plötzlichen Kindstodes in Situationen gefunden wurden, die 
mit Asphyxie verknüpft waren. Typischerweise schliefen diese Kinder im Bett der Eltern oder wurden mit von Bettzeug bedecktem Kopf aufgefunden (Pasquale-Styles et al. 2007).

Neben extrinsischen, vermeidbaren Risikofaktoren werden aktuell auch genetische Risikofaktoren diskutiert. Ausgehend von der Annahme, dass der Plötzliche Kindstod auf einer homöostatischen Disregulation beruht, wurden Polymorphismen in Genen, die im Zusammenhang mit autonomen Funktionen stehen, mit dem Plötzlichen Kindstod assoziiert (Lavezzi et. al. 2009, Weese-Mayer et. al. 2007).

Interessant ist auch die familiäre Häufung des Plötzlichen Kindstodes bei Zwillingen und das erhöhte Risiko in bestimmten ethnischen Gruppen. Das Risiko für den Plötzlichen Kindstod unter „Native Americans and Blacks“ in den USA ist um das 2-7fache höher als der Landesdurchschnitt. Auch bei den Aborigenees in Australien und den Maoris in Neuseeland tritt der Plötzliche Kindstod gehäuft auf (Kinney et al. 2009b).

\subsubsection{Die Theorie des Fatalen Dreiecks - englisch: Triple Risk Model}

Das „Triple Risk Model“ (Filiano und Kinney 1994) - die Theorie des Fatalen Dreiecks beschreibt den Plötzlichen Kindstod als multifaktorielles Syndrom und vereint Erkenntnisse aus Neuropathologie, Epidemiologie und Physiologie. Dabei klassifiziert das „Triple Risk Model“ drei verschiedene Gruppen von Risikofaktoren, die simultan auftretend zum Plötzlichen Kindstod führen:

1. eine zu Grunde liegende Vulnerabilität (genetische Risikofaktoren) 
2. einen exogenen Stressor (Schlafen in Bauchlage)

3. das Befinden in der kritischen Entwicklungsphase: die ersten 6 Lebensmonate, in denen das Kind dem höchsten Risiko für den Plötzlichen Kindstod ausgesetzt ist.

In den ersten 6 Lebensmonaten stellt sich der Schlaf-Wach-Rhythmus eines Kindes um und kardiorespiratorische Kontrollmechanismen unterliegen einer schnellen Entwicklung.

Das Modell geht davon aus, dass Kinder in der kritischen Entwicklungsphase mit genetischen Risikofaktoren und einer damit einhergehenden gestörten Hirnstammfunktion nicht adäquat auf exogene Stressoren reagieren können. Schläft das Kind in Bauchlage und reinhaliert $\mathrm{CO}_{2}$, kann es durch Heben und Drehen des Kopfes dem Plötzlichen Kindstod entkommen. Dieses Reaktionsvermögen funktioniert nur bei intakter Hirnstammfunktion, die das Aufwachen bei Hyperkapnie, regulatorischen Pulsanstieg, Blutdruck- und Atemfrequenzerhöhung triggert.

Das Modell erklärt außerdem die sinkende Inzidenz des Plötzlichen Kindstodes durch Aufklärungskampagnen, die den exogenen Stressor der Bauchlage entfernen (Kinney et al 2009b). 
zu Grunde liegende

Vulnerabilität

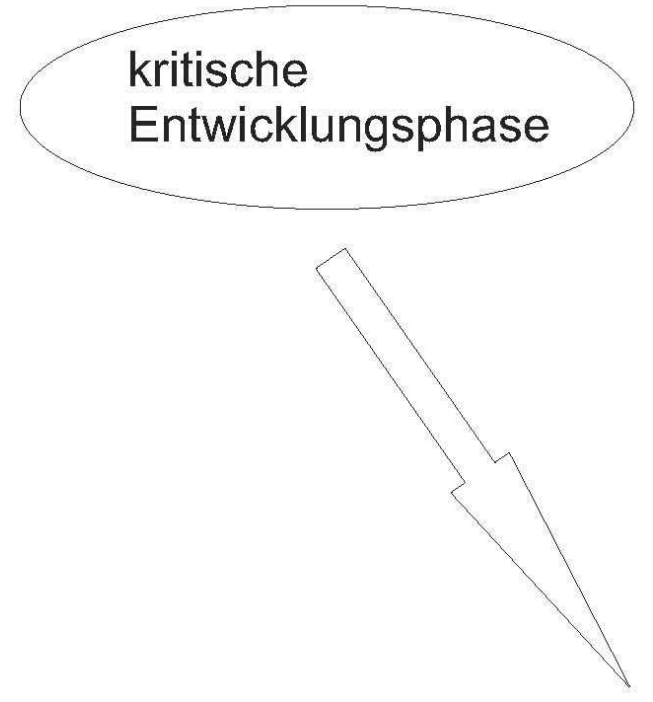

serotonerges System des Hirnstammes
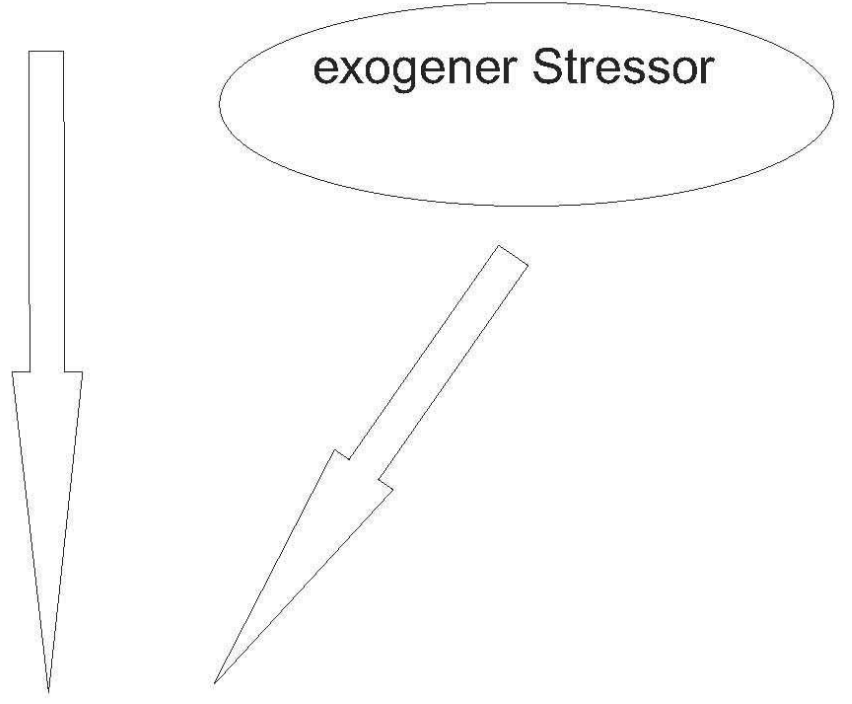

andere

Transmittersysteme

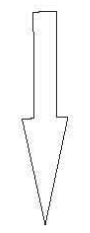

keine Aufrechterhaltung der Homöostase

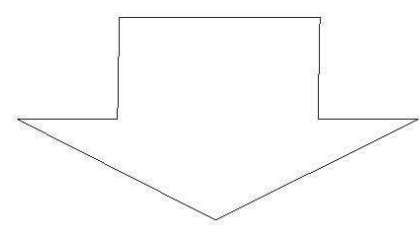

\section{Plötzlicher Kindstod}

Abb. 1 Schematische Darstellung der Theorie des fatalen Dreiecks 


\subsubsection{Pathophysiologie}

Sind alle Bedingungen des „Triple Risk Model“ erfüllt, kommt es durch Versagen der kardiorespiratorischen Kontrollfunktionen zum Plötzlichen Kindstod.

An erster Stelle steht dabei also ein Stressor wie zum Beispiel die Bauchlage eines Säuglings im Schlaf, der eine schwere Hypoxie oder eine Minderperfusion des Hirnstammes bedingt (Kinney et al. 2009b). Im zweiten Schritt hebt oder dreht das vulnerable Kind seinen Kopf nicht, um der Hypoxie zu entkommen.

Der dritte Schritt der Kaskade bedeutet das hypoxische Koma mit Bewusstseinsverlust und Areflexie (Kinney et al. 2009b). Daraufhin treten an vierter Stelle extreme Bradykardie und eine Schnappatmung auf. Bei Kindern, die trotz Anschlusses an ein Überwachungsgerät starben, konnten diese zwei Parameter an Hand der Aufzeichnungen verifiziert werden (Poets 2004).

Die Schnappatmung bei vulnerablen Kindern ist insuffizient und führt nicht aus der Hypoxie heraus.

Außerdem wachen diese Kinder als Reaktion auf Hypoxie nicht auf. Letztendlich führt die nicht unterbrochene Apnoe zum Tod. Das Aufwachen wird über serotonerge, noradrenerge, cholinerge und histaminerge Neurone im Hirnstamm, Frontalhirn und im Hypothalamus durch die Erregung des zerebralen Kortex gesteuert (Sinton und McCarley 2004).

Bei Kindern, die am Plötzlichen Kindstod versterben, sind kortikal gesteuerte Aufwachreaktionen seltener als in einer Kontrollgruppe. Subkortikale Aufwachreaktionen, die durch Neurone des Hirnstammes kontrolliert werden, sind aber häufiger bei Kindern, die an Plötzlichem Kindstod versterben (Kato et al. 2003). Daher 
sind sowohl die Erregung des zerebralen Kortex gestört als auch Hirnstammfunktionen, die die Erhöhung des Pulses, Blutdrucks und der Atmung kontrollieren. Diese Disregulation autonomer Funktionen zeigt sich in einigen Fällen schon Tage vor Eintreten des Plötzlichen Kindstodes. Dabei werden Phasen der Tachykardie beobachtet, die sich mit bradykarden Phasen abwechseln (Sridhar et al. 2003). Auch kurze Apnoephasen können schon vor Eintreten des Plötzlichen Kindstodes vorkommen.

Darüberhinaus erschweren bestimmte Risikofaktoren wie die Bauchlage oder das Rauchen während der Schwangerschaft die autonome Regulation. Das Schlafen in Bauchlage bedingt einen reduzierten Gefäßtonus und geminderte laryngeale Chemoreflexe, sowie Barorezeptorreflexe. Auch bei Kindern, deren Mütter in der Schwangerschaft geraucht haben, sind Aufwachreaktionen seltener (Kinney et al. 2009b).

\subsection{Das serotonerge System}

\subsubsection{Serotonin und Serotoninsynthese}

Serotonin ist ein wichtiger Neurotransmitter im zentralen Nervensystem, hat aber auch periphere Wirkungen wie die Beeinflussung von Gefäßmuskulatur, Bronchien und Darm. Es wird im zentralen Nervensystem und in den enterochromaffinen Zellen des MagenDarm-Trakts synthetisiert. Wie andere Neurotransmitter wird Serotonin in den Nervenendigungen in Vesikeln gespeichert und nach Stimulation in den synaptischen 
Spalt freigesetzt. Im Blut speichern Thrombozyten Serotonin und setzen es frei (Löffler et al. 2007).

Der Name Serotonin leitet sich von seiner Wirkung auf den Blutdruck ab. Der Blutserumsfaktor Serotonin führt zur Kontraktion der glatten Muskulatur der Blutgefäße und erhöht so den Blutdruck. Daher setzt sich der Name Serotonin aus „Sero"- für Serum und - „tonin“ für Tonus (Druck) zusammen.

Serotonin wird aus der essentiellen Aminosäure L-Tryptophan aufgebaut. Durch Hydroxylierung und Decarboxylierung entsteht 5-Hydroxytryptamin (=5-HT) (Löffler et al. 2007).

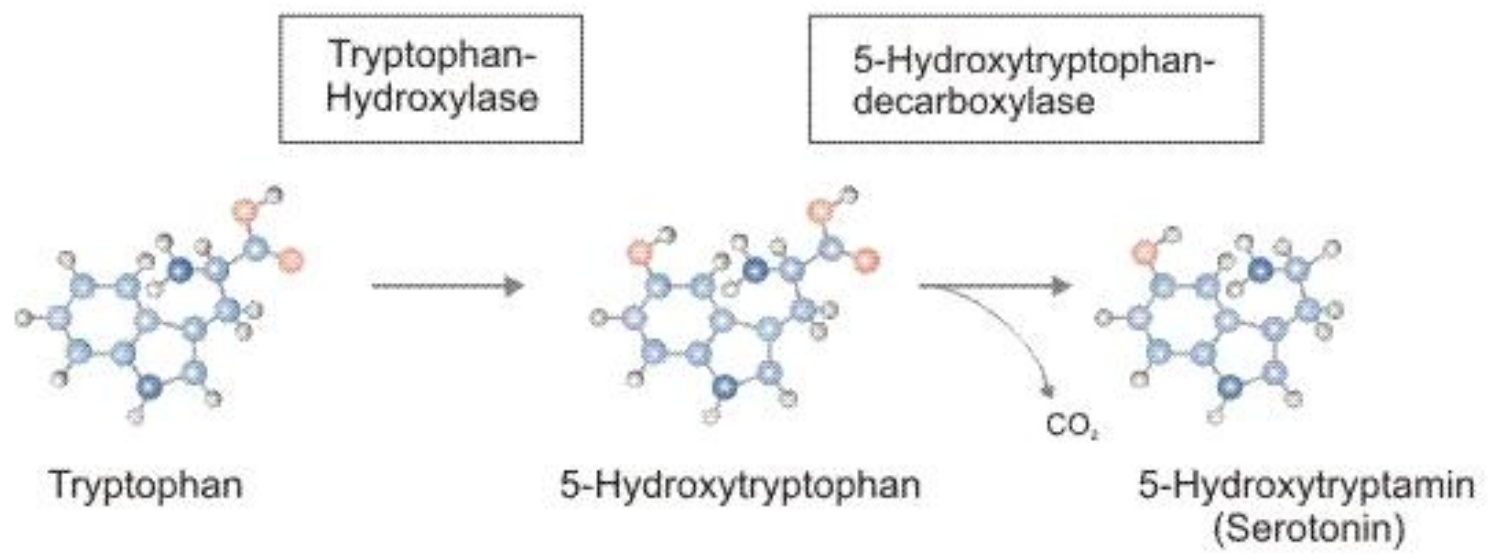

Abb. 2 Biosynthese von Serotonin. Modifizierte Abbildung aus Preuße (2005), Seite 5

Der monoaminerge Neurotransmitter Serotonin spielt eine zentrale Rolle in der Regulation von Schlaf, Atemantrieb, Chemorezeption und Temperaturhomöostase (Kinney et al. 2009a). 


\subsubsection{Serotoninrezeptoren}

Serotonin vermittelt seine Wirkung sowohl metabotrop als auch ionotrop über eine Vielzahl membranständiger Serotoninrezeptoren, die sowohl in neuralen als auch in extraneuralen Geweben exprimiert werden. Serotoninrezeptoren befinden sich auf glatter Muskulatur, Endothelzellen, Thrombozyten, Neuronen und Gliazellen (Löffler et al. 2007).

Das Interesse an selektiven Liganden für 5-HT-Rezeptoren stieg über die letzten Jahre in der Hoffnung auf einen pharmakologischen Therapieansatz zentraler Atemfunktionsstörungen an (El-Khatib et al. 2003; Guenther et al. 2009; Lalley et al 1994; Manzke et al. 2003; Manzke et al. 2009; Stettner et al. 2008; Wilken et al. 1997; Yamauchi et al. 2008a,b).

5-HT-Rezeptoren werden nach Struktur, Funktion und synaptischer Lokalisation in 7 Hauptgruppen eingeteilt: $5-\mathrm{HT}_{1}$ bis $5-\mathrm{HT}_{7}$. Insgesamt sind 14 verschiedene $5-\mathrm{HT}-$ Rezeptorsubtypen bekannt. Alle 5-HT-Rezeptorklassen sind heptahelikale G-Proteingekoppelte Rezeptoren, bis auf den $5-\mathrm{HT}_{3}$-Rezeptor, der ein ligandengesteuerter $\mathrm{Na}^{+} / \mathrm{K}^{+}-\mathrm{Kanal}$ ist.

Die G-Protein-gekoppelten Rezeptoren wirken entweder über eine Aktivierung der Phospholipase $\mathrm{C}$ oder über eine Aktivierung bzw. Hemmung der Adenylatcyclase. Am besten verstanden und untersucht sind die Rezeptorklassen der $5-\mathrm{HT}_{1}$ bis $5-\mathrm{HT}_{4}$. Mit Zahlen bezeichnet die Nomenklatur der Rezeptoren einzelne Klassen oder Subtypen, mit Buchstaben werden dann noch verschiedene Isoformen näher beschrieben (Barnes und Sharp 1999). 
Die unterschiedlichen Rezeptoren vermitteln verschiedene Effekte. 5-HT - Rezeptoren relaxieren glatte Muskulatur im Gastrointestinaltrakt und kontrahieren kraniale Blutgefäße.

5- $\mathrm{HT}_{2}-$ Rezeptoren kontrahieren glatte Muskulatur und fördern die Plättchenaggregation. 5- $\mathrm{HT}_{3}$-Rezeptoren hingegen beeinflussen Übelkeit, Erbrechen, Angst und Schmerz. 5$\mathrm{HT}_{3}$-Rezeptorantagonisten werden als Antiemetika eingesetzt (Löffler et al. 2007).

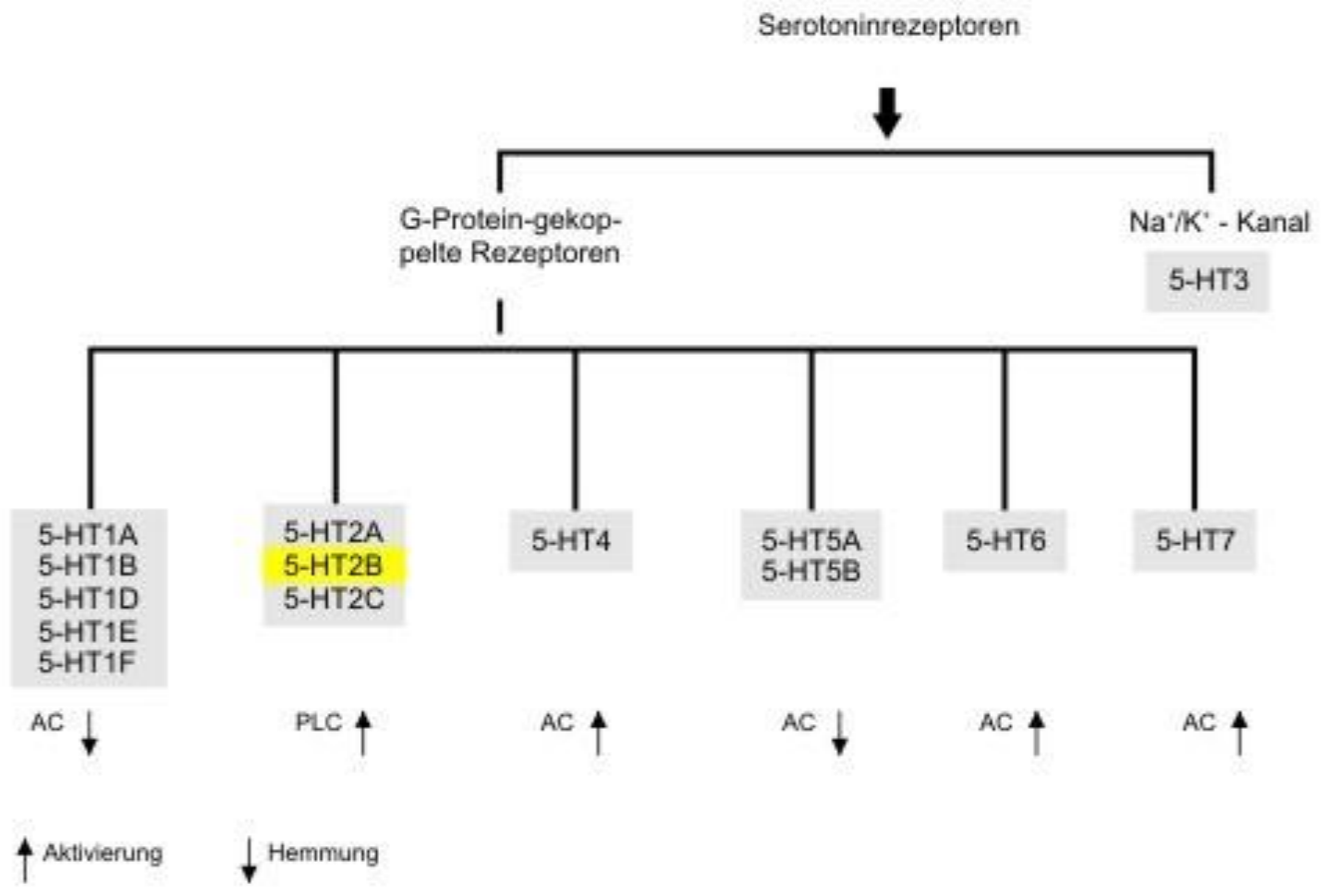

Abb. 3 Klassifikation der Serotoninrezeptoren. AC: Adenylatzyklase, PLC: Phospholypase C. Modifizierte Abbildung aus Preuße (2005), Seite 6 


\subsubsection{Verteilung und Funktion der $5-\mathrm{HT}_{2 \mathrm{~B}}-$ Rezeptoren}

Die 5- $\mathrm{HT}_{2}-$ Rezeptoren werden in die Subtypen 5- $\mathrm{HT}_{2 \mathrm{~A}}, 5-\mathrm{HT}_{2 \mathrm{~B}}$ und $5-\mathrm{HT}_{2 \mathrm{C}}$ unterteilt, die unterschiedliche Isoformen des $5-\mathrm{HT}_{2}$-Rezeptors beschreiben. Die Rezeptoren der 5$\mathrm{HT}_{2}$-Gruppe sind in ihrer molekularen Struktur, ihren pharmakologischen Eigenschaften und in der Signaltransduktion weitgehend homolog. Die Gene des $5-\mathrm{HT}_{2 \mathrm{~A}^{-}}$und des 5$\mathrm{HT}_{2 \mathrm{~B}}$-Rezeptors haben zwei Introns in der kodierenden Sequenz; das Gen des $5-\mathrm{HT}_{2 \mathrm{C}^{-}}$ Rezeptors weist dagegen drei Introns auf. Das 5- $\mathrm{HT}_{2 \mathrm{~B}}$-Rezeptor-Gen liegt auf Chromosom 2q36.3-2q37.1 (Hoyer et al. 1994).

Die aktivierten 5- $\mathrm{HT}_{2}$-Rezeptoren führen zu einer Konformationsänderung eines $\mathrm{G}_{\mathrm{q} / 11^{-}}$ Proteins, das die Aktivierung der Phospholipase C bewirkt. Über eine Erhöhung von Inositoltriphosphat wird dann die zytosolische Calciumkonzentration erhöht. Der Anstieg der intrazellulären Calciumkonzentration führt zu einer Aktivierung der Proteinkinase $C$ (Barnes and Sharp 1999; Egan et al. 1998; Martin and Humphrey, 1994; Rauser et al. 2001). 5- $\mathrm{HT}_{2}-$ Rezeptoren sind vor allem postsynaptisch lokalisiert (Cornea-Hebert et al. 1999; Palacios et al. 1990; Verge and Calas 2000) und beeinflussen an zentralen und peripheren Synapsen die Neurotransmission (Garratt et al. 1991; Wright et al. 1990).

Das Verteilungsmuster der 5-HT-Rezeptoren ist noch nicht vollständig untersucht. Ein 5$\mathrm{HT}_{2 \mathrm{~B}}-$ Rezeptorbesatz wird in der Ratte im Kleinhirn, Hypothalamus, Neokortex und in der Amygdala beschrieben (Barnes und Sharp 1999; Duxon et al. 1997). Daten zur neuroanatomischen Verteilung des $5-\mathrm{HT}_{2 \mathrm{~B}}$-Rezeptors in humanem Gewebe sind bisher in der Literatur nicht beschrieben.

Funktionell ist der 5- $\mathrm{HT}_{2 \mathrm{~B}}$-Rezeptor ein wichtiger Modulator des respiratorischen Netzwerkes. Seine Aktivierung führt zu einer Atemfrequenzsteigerung im Tiermodell 
(Manzke et al. 2005a,b). Aktivierung von $5-\mathrm{HT}_{2}$-Rezeptoren im respiratorischen Netzwerk erhöhen die Atemfrequenz neonataler Mäuse (Günther et al. 2006).

Der 5- $\mathrm{HT}_{2 \mathrm{~B}}-$ Rezeptor ist auch für die Embryonalentwicklung von entscheidender Bedeutung. So führt die Inaktivierung des $5-\mathrm{HT}_{2 \mathrm{~B}}$-Rezeptors in Mäusen zu deren Tod in der Embryonalperiode oder kurz nach der Geburt (Nebigil et al. 2001).

Eine andere Studie zeigt morphologische Entwicklungsstörungen der Neuralleiste bei Inaktivierung des $5-\mathrm{HT}_{2 \mathrm{~B}}$-Rezeptors und schreibt diesem mitogene Effekte bei der neuronalen Entwicklung zu (Choi et al. 1997).

Außerdem beeinflusst eine Stimulation des 5- $\mathrm{HT}_{2 \mathrm{~B}}$-Rezeptors die Serotoninkonzentration im Plasma (Callebert et al. 2006).

Darüberhinaus greift der $5-\mathrm{HT}_{2 \mathrm{~B}}$-Rezeptor in neurobiologischen Mechanismen bei Angst, Autismus, Schizophrenie, Migräne und Depression ein (Kennett et al. 1994,1996; McMahon und Cunningham 2001). Außerhalb des Gehirns ist der 5- $\mathrm{HT}_{2 \mathrm{~B}}$-Rezeptor involviert in die Ätiologie der pulmonalen Hypertension (Hamal et al. 2010).

\subsubsection{Das Serotonerge System und seine Bedeutung für den Plötzlichen Kindstod}

Serotonerge Neurone bilden ein räumlich weitverzweigtes Netzwerk zur Regulation neuronaler Aktivität und zahlreicher Funktionen des autonomen Nervensystems. Dabei wird eine rostrale von einer kaudalen Gruppe serotonerger Neurone abgegrenzt.

Die rostrale Gruppe serotonerger Neurone befindet sich im Mesenzephalon. Ihre Neurone projizieren in den zerebralen Kortex, den Thalamus, den Hypothalamus, die Basalganglien, den Hippokampus und in die Amygdala und modulieren Gedächtnis, 
Stimmung, motorische Aktivität, zerebralen Blutfluss und Weckreaktion (Tork and Hornung 1990).

Die kaudale Gruppe ist im Rhombenzephalon lokalisiert. Die Somata ihrer serotonergen Neurone sind an der ventralen Oberfläche im Nucleus arcuatus und vor allem in den Raphekernen zu finden, die medial und lateral im Hirnstamm lokalisiert sind.

Die Raphekerne lassen sich weiter unterteilen in die Gruppe der deszendierenden Neurone aus der pontomedullären Gruppe: Nucleus raphe magnus, Nucleus raphe obscurus, Nucleus raphe pallidus und in die Gruppe der aszendierenden Neurone aus der mesopontinen Gruppe: Nucleus raphe dorsalis und Nucleus raphe medialis (Benninghoff und Drenckhahn 2004) .

Von dort strahlen Axone in das Rückenmark, Kleinhirn und andere Regionen des Hirnstammes aus, versorgen diese mit Serotonin und steuern so die Aktivität der Serotoninrezeptor-tragenden Neurone. Damit haben serotonerge Neurone der kaudalen Gruppe entscheidenden Einfluss auf respiratorische Funktionen und das autonome Nervensystem. Diese Neurone projizieren in respiratorische Kerngebiete wie den PräBötzinger-Komplex, der als Atemrhythmusgenerator gilt, und in den Nucleus hypoglossus, der die Durchgängigkeit der oberen Atemwege reguliert. Über den Nucleus tractus solitarius werden Barorezeptor- und laryngealer Chemorezeptorreflex gesteuert. Außerdem innervieren die serotonergen Neurone der kaudalen Gruppe das Rückenmark und beeinflussen so Blutdruck, Puls und braunes Fettgewebe, das dem Säugling zur Wärmeproduktion dient (Kinney 2009). 


\subsection{Fragestellung und Zielsetzung}

Die vorliegende Arbeit beschäftigt sich mit der immunhistochemischen Analyse des 5$\mathrm{HT}_{2 \mathrm{~B}}$-Rezeptorbesatzes in der Medulla oblongata und damit mit einem Baustein des serotonergen Systems.

Das serotonerge System in der Medulla oblongata umfasst serotonerge Neurone in der Formatio reticularis, wie die medialen und lateralen Raphékerne, und Regionen an der ventralen Oberfläche, die Atem-, Kreislaufregulation und viele weitere autonome Funktionen kontrollieren.

Mangelhafte kardiorespiratorische Kontrolle und das Fehlen einer adäquaten Arousalreaktion als Antwort auf profunde Hypoxie können beim Plötzlichen Kindstod beobachtet werden (Kato et al. 2003, Sridhar et al. 2003). Ein wichtiger Faktor in der Vermittlung der Arousalreaktion ist Serotonin, das als Neurotransmitter auch eine zentrale Rolle in der Regulation von Atemantrieb, Chemorezeption und Temperaturhomöostase spielt (Berner et al. 1999, Darnall et al. 2005, Henderson et al. 2000, Messier et al. 2004, Richerson 2004). Da Serotonin an der Regulation der Aspekte beteiligt ist, die in Verbindung mit SIDS diskutiert und beobachtet werden, kommt diesem Neurotransmitter möglicherweise eine Schlüsselfunktion in der Pathogenese des Plötzlichen Kindstodes zu.

Unterschiede im 5- $\mathrm{HT}_{1 \mathrm{~A}}-$ Rezeptorbesatz und Rezeptordichte konnten bereits gezeigt werden (Paterson et al. 2006). Die Bedeutung anderer Subtypen serotonerger Rezeptoren für die Pathogenese des Plötzlichen Kindstodes ist bisher unbekannt. Aus diesem Grund wurde in dieser Arbeit der Rezeptorbesatz und die Rezeptordichte des Serotoninrezeptorsubtyps, 5- $\mathrm{HT}_{2 \mathrm{~B}}$-Rezeptors, im Hirnstamm von an natürlichem 
Kindstod verstorbenen Säuglingen im Vergleich zu Kontroll-Fällen untersucht. Ziel dieser Arbeit ist es, die molekularen Grundlagen des Plötzlichen Kindstodes besser zu verstehen.

\section{Material und Methoden}

\subsection{Material}

Die verwendeten Chemikalien, Antikörper, Zubehör und Untersuchungsgeräte werden im Folgenden aufgelistet.

\subsubsection{Verwendete Chemikalien}

Bovines Serumalbumin, Fraktion 5, (98\%): Carl Roth GmbH + Co. KG, Karlsruhe Chrom(III)-kaliumsulfat * $12 \mathrm{H}_{2} \mathrm{O}$ : E. Merck, Darmstadt

DAB, Diaminobenzidintetrahydrochlorid (97\%ig): Sigma Chemie GmbH

DePeX, permanentes Eindeckmedium: Serva Feinbiochemika GmbH

Dinatriumhydrogenphosphatanhydrat: Carl Roth GmbH + Co. KG, Karlsruhe

Essigsäure (99-100\%): Merck KGaA, Darmstadt

Ethanol (99,8\%ig) : E. Merck, Darmstadt

Extran MA 01 alkalisch: Merck KGaA, Darmstadt

Gelatine gepulvert: E. Merck, Darmstadt

Natriumchlorid (99,9\%): Carl Roth GmbH + Co. KG, Karlsruhe 
Natriumdihydrogenphosphat ${ }^{*} \mathrm{H}_{2} \mathrm{O}$ : Merck KGaA, Darmstadt

Natriumhydroxid p.A. : Merck KGaA, Darmstadt

Paraformaldehyd: Sigma-Aldrich $\mathrm{GmbH}$, Steinheim

10xPBS (Phosphate Buffered Saline):

$\mathrm{pH} 7.4 ; 1,3 \mathrm{~mol} \mathrm{NaCl} ; 70 \mathrm{mmol} \mathrm{Na} 2 \mathrm{HPO}_{4} ; 30 \mathrm{mmol} \mathrm{NaH} \mathrm{PO}_{4}$

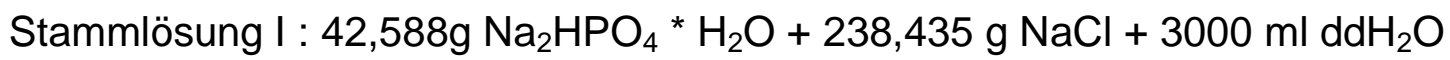

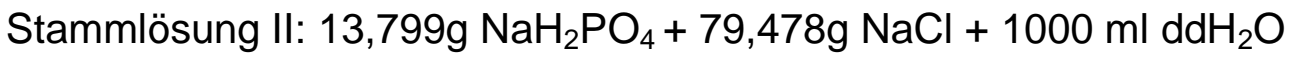

für $2000 \mathrm{ml}$ 1xPBS wurden $165 \mathrm{ml}$ Stammlösung I und $35 \mathrm{ml}$ Stammlösung II mit 1800 $\mathrm{ml}$ destilliertem Wasser gemischt und der $\mathrm{pH}$ Wert auf 7.4 mit 1 molarer $\mathrm{NaOH}$-Lösung bzw. 1 molarer Salzsäure eingestellt.

Saccharose, reinst: Merck KGaA, Darmstadt

Salzsäure, rauchend (37\%ig): E. Merck

Thionin : Merck KGaA, Darmstadt

Thionin-Lösung: $100 \mathrm{ml} 1$ molare Essigsäure $+36 \mathrm{ml} 1$ molare $\mathrm{NaOH}$-Lösung $+864 \mathrm{ml}$ $\mathrm{ddH}_{2} \mathrm{O}$ werden auf $60^{\circ} \mathrm{C}$ unter Rühren erhitzt. Dann werden $1,25 \mathrm{~g}$ Thionin hinzugegeben. Nach einer Stunde rühren wird die Lösung heiß filtriert.

Triton X-100: Carl Roth GmbH + Co. KG, Karlsruhe

Wasserstoffperoxid (35\%ig): Merck KGaA, Darmstadt

Xylol (Isomere) (99,8\%): Carl Roth GmbH + Co. KG, Karlsruhe

\subsubsection{Verwendete Antikörper}

polyklonaler Anti-Calbindin-Antikörper aus dem Kaninchen (Katalognummer: AB1778), Chemicon 
polyklonaler Anti-FoxP2-Antikörper aus dem Kaninchen (Katalognummer: ab16046), Abcam

monoklonaler Anti-GFAP-Antikörper aus der Maus (Produktnummer: G3893), Sigma monoklonaler Anti-MeCP2-Antikörper aus der Maus (Produktnummer: M7443), Sigma polyklonaler Anti-Serotonin-Antikörper aus dem Kaninchen (Produktnummer: S5545), Sigma polyklonaler 5-HT 7 -Rezeptor-Antikörper aus dem Kaninchen (Katalognummer 1-800662-2616), Oncogene Science

Monospezifisches polyklonales $5-\mathrm{HT}_{4 \mathrm{a}}$-Rezeptor-Antiserum aus dem Kaninchen wurde in der Abteilung Neuro- und Sinnesphysiologie, Humboldtallee 23, 37075 Göttingen produziert und zur Verfügung gestellt. Das Antiserum wurde in demselben Labor von Dr. Dr. rer. nat. Till Manzke affinitätschromatographisch gereinigt (Manzke et al. 2003,Manzke et al. 2008).

Monospezifisches polyklonales $5-\mathrm{HT}_{2 \mathrm{~B}}$-Rezeptor-Antiserum aus dem Kaninchen wurde in der Abteilung Neuro- und Sinnesphysiologie, Humboldtallee 23, 37075 Göttingen produziert und zur Verfügung gestellt. Das Antiserum wurde in demselben Labor von Dr. Dr. rer. nat. Till Manzke affinitätschromatographisch gereinigt.

Dabei wurden die Kaninchen mit dem Peptid der zweiten intrazellulären Schleife des 5$\mathrm{HT}_{2 \mathrm{~B}}$ Rezeptors der Ratte mit der Aminosäuresequenz immunisiert $\left(\mathrm{NH}_{2}^{-}\right.$ CAISLDRYIAIKKPIQ-COOH). Die Struktur des aus sieben Transmembrandomänen aufgebauten Rezeptors und die ausgewählte Aminosäuresequenz zur Immunisierung zeigt Abbildung 4. 


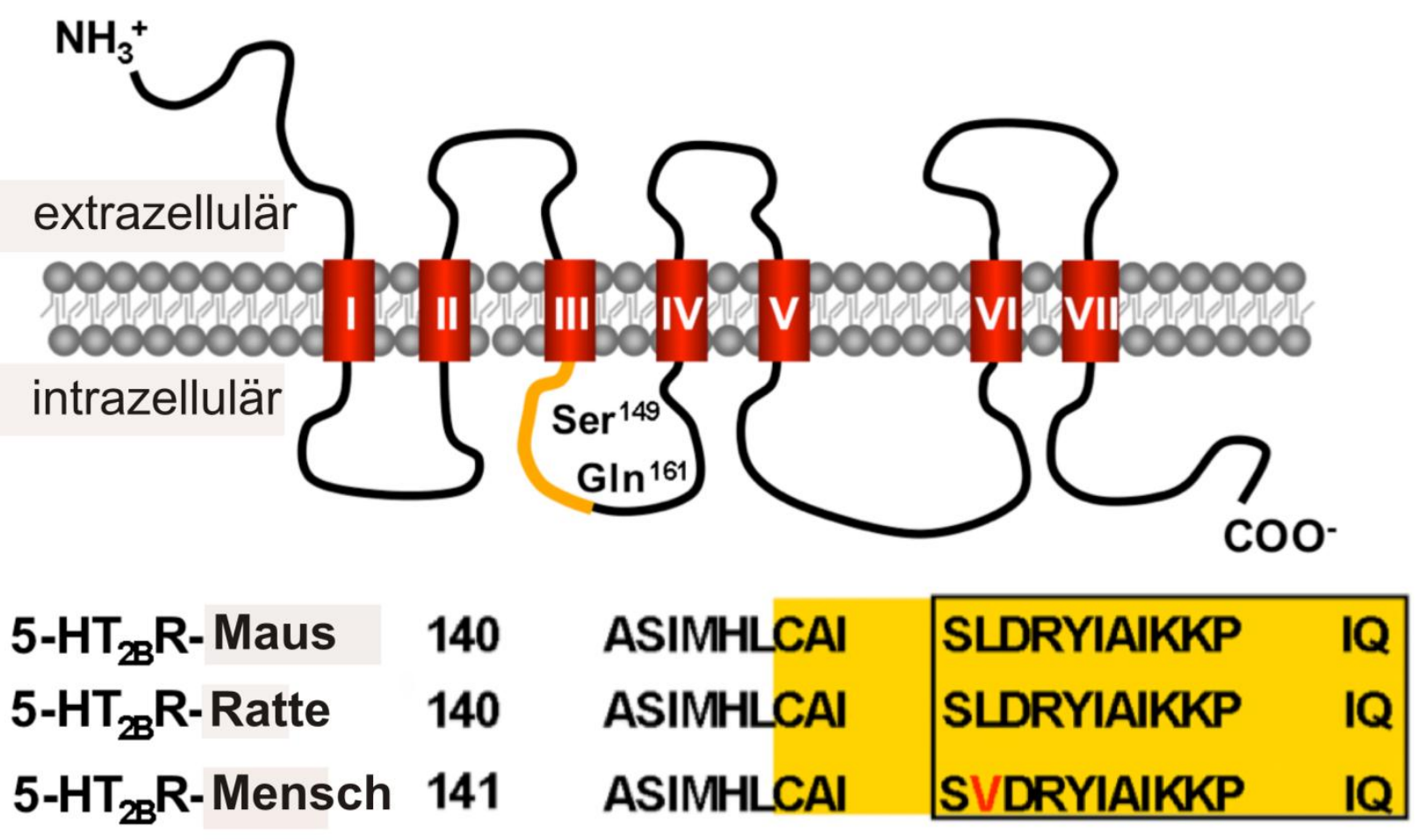

Abb. 4 Der 5- $\mathrm{HT}_{2 \mathrm{~B}}-$ Rezeptor ist ein heptahelikaler Rezeptor. Die 7 Transmembrandomänen sind als rote Zylinder dargestellt (I-VII). Der produzierte Antikörper richtet sich gegen die Aminosäuresequenz (Cys ${ }^{146}-\mathrm{Gln}^{161} ; \mathrm{NH}_{2}$-CAISLDRYIAIKKPIQ-COOH) der zweiten intrazellulären Schleife (gelb markiert). Das Peptid der Ratte weist 100\%ige Homologie mit dem der Maus auf. Der Unterschied in der menschlichen Sequenz ist rot markiert. Modifizierte Abbildung aus Manzke (2004), Seite 50

Monospezifisches polyklonales $5-\mathrm{HT}_{5 \mathrm{~B}}$-Rezeptor-Antiserum aus dem Kaninchen wurde in der Abteilung Neuro- und Sinnesphysiologie, Humboldtallee 23, 37075 Göttingen produziert und zur Verfügung gestellt. Das Antiserum wurde in demselben Labor von Dr. Dr. rer. nat. Till Manzke affinitätschromatographisch gereinigt. 
Peroxidasekonjugierter polyklonaler Antikörper anti-Kaninchen IgG $(H+L)$ aus dem Esel (Seriennummer: 711-035-152), Dianova GmbH, Hamburg

Peroxidasekonjugierter polyklonaler Antikörper anti-Maus $\lg G(H+L)$ aus dem Esel (Seriennummer: 715-005-150), Dianova GmbH, Hamburg

\subsubsection{Verwendete Geräte}

Coolescope, Digitalmikroskop, Nikon

Gefriermikrotom, Frigocut Modell 1206: Frigocut, Reichert-Jung, Deutschland

pH-Meter: WTW pH 197, Wissenschaftlich-Technische Werkstätten GmbH, über Schütt Labortechnik Göttingen

Rührer: Heidolph MR Hei-Standard, Heidolph Instruments Schwabach

Schüttler: Heidolph Rotamax 120, Heidolph Instruments Schwabach

Vortexer: Vortex-Genie 2, Scientific Industries, über Schütt Labortechnik Göttingen

Waage: Sartorius bis $160 \mathrm{~g}$, Sartorius Ag Göttingen

Waage: Sartorius BP61S bis 61g, Sartorius Ag Göttingen

Zeiss 494, Lichtmikroskop

\subsubsection{Computersoftware}

CorelDraw Graphics Suite X3 (2005)

Microsoft Office Excel (2003)

GraphPadPrism, Version 5

Neurolucida, Version 7
Corel Corporation

Microsoft Corporation

GraphPad Software

MBF Bioscience 
NIS Elements, Version 2.1

Adobe Photoshop CS 2, Version 9.0

Microsoft Office Word (2003)
Nikon Imaging Software

Adobe Systems

Microsoft Corporation

\section{$\underline{2.2 \text { Methoden }}$}

\subsubsection{Gewebsgewinnung}

Die Hirnstämme der an Plötzlichem Kindstod verstorbenen Säuglinge und der KontrollFälle stammen aus dem Archiv der Rechtsmedizin. Die Hirnstämme wurden bei der Sektion entnommen und in Paraformaldehyd konserviert. Es handelt sich hierbei um eine Immersionsfixierung, bei der das Gewebe direkt in die Fixierlösung gegeben wird. Die Sammlung umfasst Proben aus den Jahren 1989 bis heute.

\subsubsection{Stichprobe}

Retrospektiv wurden Fälle, die in den Jahren zwischen 1998 und 2009 diagnostiziert wurden, ausgewählt. Aus den Asservaten der Rechtsmedizin wurden die Hirnstämme der ausgewählten Fälle zur immunhistochemischen Untersuchung entnommen. Dabei konnten die als SIDS diagnostizierten Proben nach der Klassifizierung Krous' in 2 Gruppen aufgeteilt werden (Krous et al. 2004). Die eine Gruppe umfasst Säuglinge, die als SIDS IA bezeichnet werden. Unter diese Gruppe fallen Säuglinge, bei denen keine zusätzlichen klinischen Auffälligkeiten bei der Obduktion bemerkt wurden. Die Gruppe der als SIDS II klassifizierten Säuglinge beinhaltet auch Fälle, bei denen Zeichen einer 
milden Infektion festgestellt werden konnten, die jedoch nicht ursächlich für den plötzlichen Tod sein können (Krous et al. 2004).

Es wurden 22 Hirnstämme von an Plötzlichem Kindstod verstorbenen Säuglingen der Kategorie SIDS IA, 12 Hirnstämme von an Plötzlichem Kindstod mit entzündlicher Komponente verstorbenen Säuglingen der Kategorie II und 5 Hirnstämme von Säuglingen mit anderer Todesursache analysiert. Diese 5 Hirnstämme dienten als Kontrollen. Eine Übersicht über die Todesursache, das Alter und Geschlecht der Fälle in den einzelnen Gruppen zeigt folgende Tabelle 1.

Tabelle 1 Fallprofil der drei untersuchten Gruppen. m: Monate alt, n: Fallzahl, SIDS IA: Plötzlicher Kindstod, SIDS II: Plötzlicher Kindstod mit entzündlicher Komponente, der Altersmedian ist in eckigen Klammern angegeben: [ ]

\begin{tabular}{l|ccll} 
Fälle $(\mathrm{n})$ & männlich & weiblich & \multicolumn{1}{c}{ Alter } & \multicolumn{1}{c}{ Todesursache } \\
\hline \hline SIDS IA (22) & 15 & 7 & $1 \mathrm{~m}-9 \mathrm{~m}[4 \mathrm{~m}]$ & Plötzlicher Kindstod \\
\hline & & & $\begin{array}{l}\text { Plötzlicher Kindstod } \\
\text { mit Zeichen einer } \\
\text { milden }\end{array}$ \\
& & & $1 \mathrm{~m}-11 \mathrm{~m} \mathrm{[3m]}$ & $\begin{array}{l}\text { Entzündung } \\
\text { SIDS II (12) }\end{array}$ \\
\hline & 9 & 3 & & $\begin{array}{l}\text { Myokarditis } \\
\text { Nephritis }\end{array}$ \\
& & & & $\begin{array}{l}\text { Vitium (2) } \\
\text { Thymusvergrößerung }\end{array}$
\end{tabular}




\subsubsection{Erzeugung frei schwimmender Gefrierschnitte}

Geräte: Gefriermikrotom, Skalpell, feiner Pinsel, transparente Eierschalen, schwarze Unterlage

Lösungen: PBS, Saccharose-Lösung (30\%) in PBS

Mit dem Skalpell wurde der Teil des Hirnstamms en bloc herausgeschnitten, der die gesamte Olive enthält. Die obere Schnittlinie verlief horizontal durch kaudale Abschnitte des Pons, die untere Schnittlinie verlief horizontal auf Höhe des ersten Spinalnerven. Die Schnittanzahl pro Probe belief sich auf ca. 500 Schnitte. Insgesamt wurden von 40 Proben 20.000 Schnitte angefertigt.

Die Infiltration der Hirnstamm-Blöcke über Nacht mit 30\%-Saccharose in PBS vermindert die Bildung von Eiskristallen beim Gefrieren des Gewebes und schont so die Gewebestruktur.

An einem Gefriermikrotom wurden die Blöcke in einem Eisblock schockgefroren, der durch Auftropfen von 30\%-Saccharose Lösung erzeugt wurde. Transversale Schnitte von $40 \mu \mathrm{m}$ Dicke wurden mit einem Pinsel in mit PBS gefülte, transparente Eierschalen transferiert. Eine schwarze Unterlage erleichterte die Sicht auf die Schnitte in den Eierschalen. Der weitere Transfer der Schnitte in Waschpuffer (PBS) und Inkubationslösungen erfolgte ebenfalls mit Hilfe eines Pinsels. 


\subsubsection{Thionin-Färbung}

Zur sicheren topographischen Orientierung und Auswahl eines geeigneten Abschnittes wurde der gesamte Pons und die Medulla oblongata eines Hirnstammes in 4 Blöcke zerlegt. Von den einzelnen Blöcken wurden $40 \mu \mathrm{m}$ dicke Schnitte angefertigt, auf Objektträger aufgezogen und nach dem Antrocknen darauf eine Thionin-Färbung nach folgendem Protokoll durchgeführt:

$\begin{array}{lll}3 & \text { Minuten } & 100 \% \text { Ethanol } \\ 3 & \text { Minuten } & 95 \% \text { Ethanol } \\ 3 & \text { Minuten } & 70 \% \text { Ethanol } \\ 3 & \text { Minuten } & 50 \% \text { Ethanol } \\ 3 & \text { Minuten } & \text { ddH }_{2} \mathrm{O} \\ 2 & \text { Minuten } & \text { Thionin-Lösung } \\ 3 & \text { Minuten } & 50 \% \text { Ethanol } \\ 3 & \text { Minuten } & 70 \% \text { Ethanol } \\ 3 & \text { Minuten } & 95 \% \text { Ethanol } \\ 3 & \text { Minuten } & 100 \% \text { Ethanol } \\ 3 & \text { Minuten } & 100 \% \text { Xylol } \\ 3 & \text { Minuten } & 100 \% \text { Xylol } \\ 3 & \text { Minuten } & 100 \% \text { Xylol }\end{array}$

Darauf folgte das Eindecken der Schnitte in permanentem Eindeckmedium ( s. 2.2.7) 


\title{
2.2.5 Immunperoxidase-Färbung
}

Bei der Immunperoxidase-Färbung wird im ersten Schritt ein spezifischer Antikörper (Primärantikörper) auf das zu untersuchende Gewebe aufgebracht. Die Primärantikörper binden an ihre Epitope. In einem zweiten Schritt wird ein Antikörper aufgetragen, der sich gegen den Primärantikörper richtet. Es ist der sogenannte Sekundärantikörper. Die Sekundärantikörper sind also gegen die Spezies des Primärantikörpers gerichtet. Die Sekundärantikörper sind hier mit einem Enzym gekoppelt, das eine Farbentstehung durch eine Enzym-Substrat-Reaktion auslöst. Es entsteht ein sichtbarer Farbstoff.

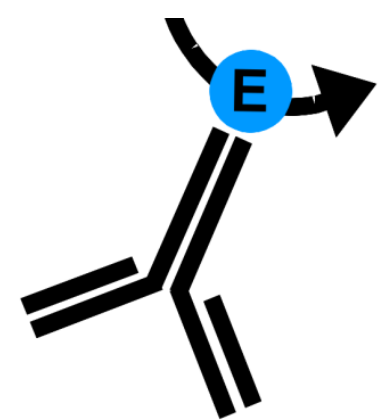

\author{
Peroxidasekonjugierter \\ Sekundärantikörper \\ (aus Esel, anti Kaninchen)
}

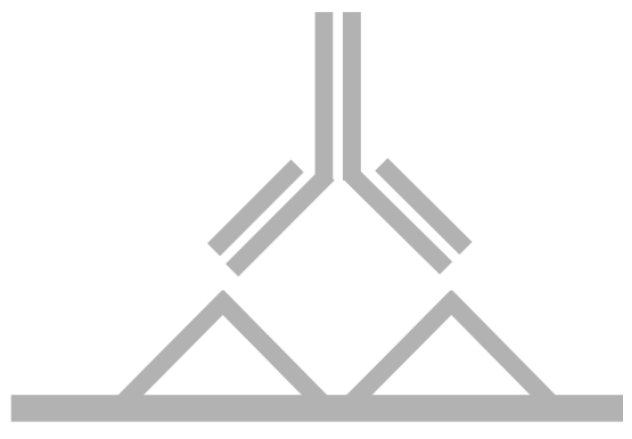

Primärantikörper (aus Kaninchen)

\section{Antigen (5- $\mathrm{HT}_{2 \mathrm{~B}}-$ Rezeptor)}

\begin{abstract}
Abb. 5 Graphische Darstellung der Immunperoxidase-Färbung. Der Primärantikörper bindet an das Antigen. Nach Binden des Sekundärantikörpers an den Primärantikörper entsteht durch das an den Sekundärantikörper gekoppelte Enzym, Peroxidase, durch den Umsatz von $\mathrm{H}_{2} \mathrm{O}_{2}$ ein sichtbarer Farbstoff. Modifizierte Abbildung aus Manzke (2004), Seite 22
\end{abstract}


Nach Fixierung der Hirnstämme in Paraformaldehydlösung können Antigene durch Denaturierung der Proteine maskiert sein. Daher wurden die Schnitte wie im Folgenden beschrieben in Triton X-100 inkubiert. Das nicht-ionische Detergens Triton X-100 gehört zu den Polyoxyethylenoctylphenol-Detergenzien und eignet sich gut zur Demaskierung von Proteinen.

Anschließend inkubierten die Schnitte in einer Lösung aus Primärantikörper und bovinem Serumalbumin (BSA), das unspezifische Bindungen der Antikörper vermeiden soll.

Die Schnitte wurden 6 mal 5 Minuten lang in PBS gewaschen und anschließend 30 Minuten in 0,2\%igem Triton-X-100 permeabilisiert. Anschließend inkubierten die Schnitte in einer Lösung aus 2\%igem bovinem Serumalbumin und dem polyklonalen Primärantikörper gegen den $5-\mathrm{HT}_{2 \mathrm{~B}}$-Rezeptor (Verdünnung 1:500) bei $4^{\circ} \mathrm{C}$ über Nacht. Nach erneutem sechsmaligen Waschen in PBS für 5 Minuten wurden die Schnitte bei Raumtemperatur für 2,5 Stunden in 2\% BSA in PBS mit dem peroxidasekonjugierten Sekundärantikörper anti-Kaninchen aus dem Esel inkubiert.

\subsubsection{Peroxidasereaktion in Diaminobenzidin-Lösung (DAB)}

Der Peroxidase wird Wasserstoffperoxid als Substrat angeboten, das sie in Wasser und Sauerstoff spaltet. Der Sauerstoff oxidiert Diaminobenzidin. Die oxidierte Form des Diaminobenzidins ist braun. Da das Antigen indirekt mit Peroxidasemolekülen markiert ist, findet der Farbumsatz genau an der Stelle statt, an dem der Primärantikörper das Antigen gebunden hat. 
Die markierten Zellen sind lichtmikroskopisch detektierbar und die Schnitte können sehr lange Zeit gelagert werden, ohne dass der Farbstoff ausbleicht.

Geräte: Pinsel, transparente Eierschalen

Lösungen: PBS (Waschpuffer), DAB-Lösung: $500 \mu \mathrm{l}$ Stammlösung (75 mg DAB in 1,5 $\mathrm{ml}$ PBS) in $30 \mathrm{ml} \mathrm{PBS,} \mathrm{30 \%} \mathrm{Wasserstoffperoxid}$

Die Schnitte wurden erneut 6 mal 5 Minuten lang in PBS gewaschen und dann in Eierschalen mit 3ml gefilterter DAB-Lösung gegeben. Durch Zugabe von $4 \mu \mathrm{H}_{2} \mathrm{O}_{2}$ (35\%ig) wurde die enzymatische Reaktion gestartet.

Zum Stoppen der Farbreaktion wurden die Schnitte in PBS-Lösung transferiert und anschließend auf gelatinierte Objektträger aufgezogen. Über Nacht trockneten die Schnitte auf den Objektträgern.

\subsubsection{Eindecken der Schnitte in permanente Eindeckmedien}

Der Wassergehalt der Hirnstammschnitte verursacht störende Lichtbrechungen, da Wasser einen anderen Brechungsindex besitzt als Glas. Deshalb müssen die Schnitte in Ethanol dehydrogeniert werden. Das entzogene Wasser wird danach durch Xylol ersetzt, das den gleichen Brechungsindex wie Glas besitzt.

Geräte: Pinsel, transparente Eierschalen, schwarze Unterlage, Glasschalen Lösungen: Ethanol, Xylol, destilliertes Wasser, DePeX-Kunstharz 
Durch eine aufsteigende Ethanolreihe (2x 5 Minuten 50\% Ethanol, 2x 5 Minuten 80\% Ethanol, 2x 5 Minuten 99,9\% Ethanol) wurden die Schnitte dehydrogeniert. Anschließend wurde der Alkohol durch ein 15 Minuten dauerndes Bad in Xylol ersetzt. Die noch mit Xylol benetzten Schnitte auf den Objektträgern wurden mit DepexKunstharz, einem permanenten Eindeckmedium, eingedeckt.

\subsubsection{Gelatinieren der Objektträger}

Zum besseren Halt der Schnitte auf den Objektträgern wurden diese mit einem dünnen Film aus Gelatine überzogen.

Geräte: Heizplatte, Thermometer, Bechergläser, Objektträgerhalter, Filter Lösungen: Extran MA $01\left(10 \mathrm{ml}\right.$ in $\left.990 \mathrm{ml} \mathrm{H}_{2} \mathrm{O}\right), 5 \mathrm{~g}$ Gelatine in $11 \mathrm{ddH}_{2} \mathrm{O}+0,5 \mathrm{~g}$ $\mathrm{CrKO}_{8} \mathrm{~S}_{2} * 12 \mathrm{H}_{2} \mathrm{O}$

Die Objektträger inkubierten über Nacht in Extran MA 01. Am nächsten Tag wurden die Objektträger unter fließendem Wasser 3 Stunden gewaschen. Die Gelatine wurde bei $55^{\circ} \mathrm{C}$ in einem Liter destilliertem Wasser gelöst und $0,5 \mathrm{~g} \mathrm{CrKO}_{8} \mathrm{~S}_{2}{ }^{*} 12 \mathrm{H}_{2} \mathrm{O}$ zugegeben. Nach Filtern der Lösung wurden die Objektträger 30 Sekunden lang in die noch warme Lösung eingetaucht. Bevor die Hirnstammschnitte aufgezogen wurden, trockneten die Objektträger 24 Stunden. 


\subsubsection{Analyse der Zelldichte mit dem Coolescope und digitale Bildverarbeitung}

Die anatomische Orientierung und die Lage der einzelnen Kerngebiete wurde korrespondierend mit dem Atlas of the Human Brainstem (Paxinos und Huang 1995) festgelegt. Eine Übersichtsdarstellung der einzelnen Schnitthöhen (Abbildung 6) erfolgte in Zusammenschau mit dem 2. Band Anatomie (Benninghoff und Drenckhahn 2004).

Die digitale Erfassung und Analyse der einzelnen Kerngebiete erfolgte durch das Digitalmikroskop Nikon Coolescope. Es wurden Farbphotographien in den Vergrößerungsstufen (x2, x4, x20, x40) erstellt und im Dateiformat „tiff“, tagged image file format (englisch: Rasterbilddateiformat), abgespeichert. Zur sicheren Vergleichbarkeit der Aufnahmen wurde bei der Arbeit mit dem Digitalmikroskop unter konstanten Beleuchtungsbedingungen gearbeitet.

Nach einer Übersichtsaufnahme des gesamten Schnittes wurden die Kerngebiete (Nucleus hypoglossus, Nucleus raphe obscurus, Nucleus cuneatus externus, laterale retikuläre Formation) herausvergrößert (300x, 75x, 150x, 75x) und die markierten Zellen auf dem gesamten Bildausschnitt manuell ausgezählt. Die ausgezählte Fläche war so bei jeder Probe gleich groß. Damit ergibt sich die Zellzahl pro definierter Fläche. Bei der Analyse des Nucleus hypoglossus wurden die markierten Zellen auf einer Fläche von $0,009 \mathrm{~cm}^{2}$, bei der Analyse des Nucleus raphe obscurus und der lateralen Formatio reticularis auf einer Fläche von $0,139 \mathrm{~cm}^{2}$ und bei der Analyse des Nucleus cuneatus externus auf einer Fläche von $0,062 \mathrm{~cm}^{2}$ ausgezählt. Das Kerngebiet des Nucleus hypoglossus, des Nucleus raphe obscurus und der lateralen retikulären Formation wurde dabei immer in seiner Gesamtheit erfasst. Vom Nucleus cuneatus externus wurde wegen seiner Größe ein Ausschnitt aus dem Zentrum des Kerngebietes erfasst. 
Ein spezielles optisches Mikroskop mit PC-Anschluss und die Software Neurolucida ermöglichten das Erstellen von Plotttafeln. Die Grenzen der Kerngebiete wurden dabei manuell festgelegt und die Neurone manuell ausgezählt. Die Software ermöglichte auch eine Angabe der Zellzahl pro Fläche zur nachvollziehbaren, quantitativen Analyse. 


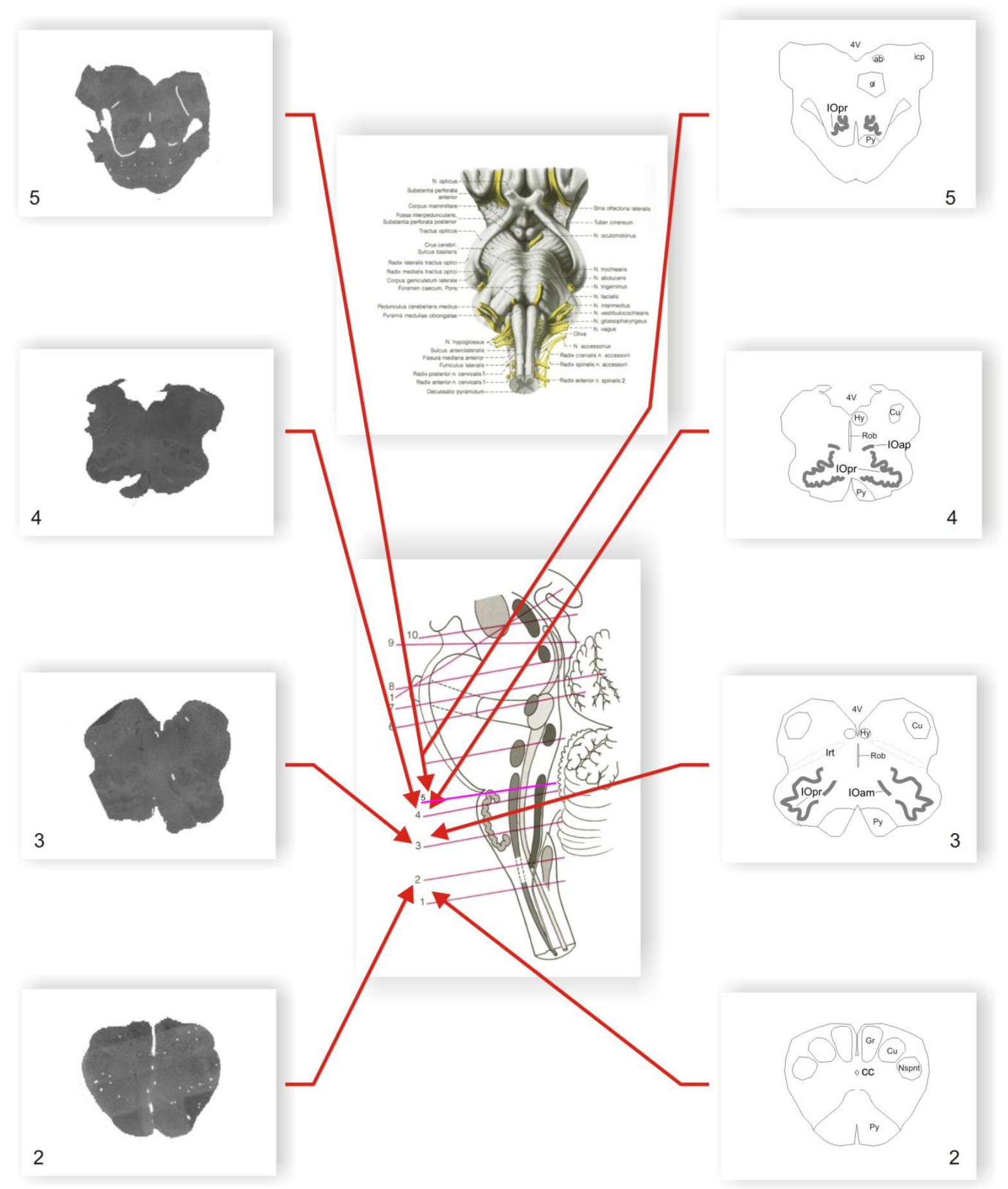

Abb. 6 Übersicht über die untersuchten Schnitthöhen der Medulla oblongata. ab: Nucleus abducens, cc: Zentralkanal, $\mathrm{Cu}$ : Nucleus cuneatus, gi: Nucleus gigantocellularis, Gr: Nucleus gracilis, Hy : Nucleus hypoglossus, icp: Pedunculus cerebellaris inferior, IOam: Nucleus olivaris accessorius medius, IOap: Nucleus olivaris accessorius posterior, IOpr: Nucleus olivaris principalis, Irt: intermediäre Zone der Formatio reticularis, Nspnt: Nucleus spinalis nervi trigemini, Py: Tractus pyramidalis, Rob: Nucleus raphe obscurus, 4V: vierter Ventrikel. Modifizierte Abbildung aus Benninghoff, Drenckhahn 2004, $332 f$ 


\subsubsection{Statistische Auswertung}

Insgesamt wurden 39 Proben untersucht, die in drei Gruppen aufgeteilt wurden: Die erste Gruppe beinhaltet 22 Proben mit der Diagnose SIDS IA, die zweite Gruppe 12 Proben mit der Diagnose SIDS II und die dritte Gruppe entsprach mit 5 Proben der Kontrollgruppe. Zur statistischen Auswertung wurde die Software GraphPad Prism verwendet. Mit dieser Software wurde der Mittelwert (M) und der Standardfehler (SEM) berechnet $(M \pm S E M)$. Für die $p$-Wertberechnung wurde ein $t$-Test für gepaarte Stichproben gewählt. „Der t-Test arbeitet mit den Populationsparametern der Streuung und des arithmetischen Mittels, die mit Hilfe der Stichprobe geschätzt werden. Er liefert eine Entscheidungshilfe dafür, ob ein gefundener Mittelwertsunterschied rein zufällig entstanden ist, oder ob es wirklich bedeutsame Unterschiede zwischen den zwei untersuchten Gruppen gibt. Mathematisch gesprochen beurteilt dieses Verfahren, ob sich zwei untersuchte Gruppen systematisch in ihren Mittelwerten unterscheiden oder nicht“ (Rasch et al. 2006, Seite 44). „Die Entscheidung über die Signifikanz erfordert die Festlegung eines Signifikanzniveaus vor der Durchführung des t-Tests. Jenes kennzeichnet die nach Ansicht des Forschers größte noch akzeptable $\alpha$-FehlerWahrscheinlichkeit." (Rasch et al. 2006, Seite 60). Als Signifikanzniveau wurde $p \leq 0,05$ festgelegt, so dass mit 5\%iger Wahrscheinlichkeit ( $\alpha$-Fehler) die Nullhypothese - es besteht kein Unterschied zwischen den Gruppen - abgelehnt wird, obwohl sie doch zutrifft. Ein auf dem 5\%-Niveau signifikantes Ergebnis wurde mit einem Sternchen $\left({ }^{\star}\right)$ gekennzeichnet. Der t-Test untersuchte jeweils Gruppenpaare im Bezug auf ein Merkmal. Das entsprach dem Vergleich der ersten Gruppe (SIDS IA) mit der 
Kontrollgruppe im Bezug auf die 5- $\mathrm{HT}_{2 \mathrm{~B}}$-Rezeptorexpression im Nucleus hypoglossus. Dementsprechend wurden die Gruppen untereinander im Bezug auf die 5- $\mathrm{HT}_{2 \mathrm{~B}^{-}}$ Rezeptorexpression in den verschiedenen Kerngebieten verglichen.

\section{Ergebnisse}

Es wurden Färbungen mit Antikörpern gegen verschiedene Strukturen der Medulla oblongata angefertigt. Dabei wurde das Bindungsmuster der im Labor von Dr. Dr. Till Manzke hergestellten Antikörper (gegen den 5- $\mathrm{HT}_{2 \mathrm{~B}}$-Rezeptor, 5- $\mathrm{HT}_{4(\mathrm{a})}$-Rezeptor, 5$\mathrm{HT}_{5 \mathrm{~B}}$-Rezeptor und 5-HT$T_{7}$-Rezeptor) mit dem kommerziell erhältlicher Antikörper (gegen Serotonin, FoxP2, Calbindin, GFAP und MeCP2) verglichen.

Zuverlässige und spezifische Signale konnten bei allen kommerziell erhältlichen Antikörpern und den Antikörpern gegen die 5- $\mathrm{HT}_{2 \mathrm{~B}^{-}}, 5-\mathrm{HT}_{4(\mathrm{a})^{-}}$und 5- $\mathrm{HT}_{7}$-Rezeptoren erreicht werden. Die Ursache für das fehlende Signal bei den anderen Antikörpern kann in deren Spezifität begründet sein. Außerdem könnte auch das Milieu nach den oben erläuterten Versuchsbedingungen für die Antikörperbindung nicht optimal gewesen sein. Um auszuschließen, dass das Signal nicht allein durch den Sekundärantikörper ausgelöst werden kann, wurden jeweils Kontrollfärbungen nur mit dem Zweitantikörper angefertigt. 


\subsection{Die Topographie der 5- $\mathrm{HT}_{2 \mathrm{~B}}-$ Rezeptoren in der Medulla oblongata}

Bei der anatomischen und pathologischen Begutachtung der einzelnen Schnittebenen des Hirnstammes wurden gehäufte Zellansammlungen von $5-\mathrm{HT}_{2 \mathrm{~B}}$-rezeptortragenden Zellen Kerngebieten zugeordnet. Die Zuordnung erfolgte an Hand des Atlas of the Human Brainstem (Paxinos und Huang 1995). Dabei wurde ein Ausschnitt des Hirnstammes untersucht, der die Olive beinhaltet. Eine Übersicht der untersuchten Schnitthöhen ist in Abbildung 6 dargestellt. Der untersuchte Bereich reichte von dem kaudalen Pons bis in die kraniale Medulla spinalis. Von den insgesamt 20.000 angefertigten Schnitten wurden 2000 mit dem Antikörper gegen den 5-HT $\mathrm{T}_{2 \mathrm{~B}}$-Rezeptor behandelt.

Eine erste anatomische Orientierungshilfe bot der große Kernkomplex der Olive im ventrolateralen Tegmentum der Medulla oblongata. Der Hauptkern der Olive, der Nucleus olivaris principalis und seine Beziehung zu seinen beiden Nebenkernen, dem dorsalen Nucleus olivaris accessorius und dem medialen Nucleus olivaris medialis erleichterten die Bestimmung der Schnitthöhe.

Die mediale Nebenolive legt sich dem Hauptkern wie eine Platte an. Zwischen ihr und dem Hauptkern ziehen die Fasern des Nervus hypoglossus nach ventral. Der Nucleus nervi hypoglossi liegt auf dieser Höhe mediodorsal im Boden der Rautengrube im Trigonum nervi hypoglossi.

In der Medianlinie sind die Raphekerne lokalisiert, deren Name sich von dem Wort Naht ableitet, da die sich dort kreuzenden Fasern wie vernäht erscheinen (Benninghoff und Drenckhahn 2004). 
Außerdem gab die Ausdehnung des gut abgrenzbaren laterodorsal liegenden Nucleus cuneatus externus Hinweise auf die exakte Schnitthöhe.

Viele immunopositive, $5-\mathrm{HT}_{2 \mathrm{~B}}$-rezeptortragende Zellen wurden in der Region des Nucleus hypoglossus (Abbildung 7), des Nucleus cuneatus externus (Abbildung 8) und des Nucleus raphe obscurus (Abbildung 9) gefunden. Einige 5- $\mathrm{HT}_{2 \mathrm{~B}}-$ rezeptortragende Zellen lagen auch in der lateralen retikulären Formation (Abbildung 10). 


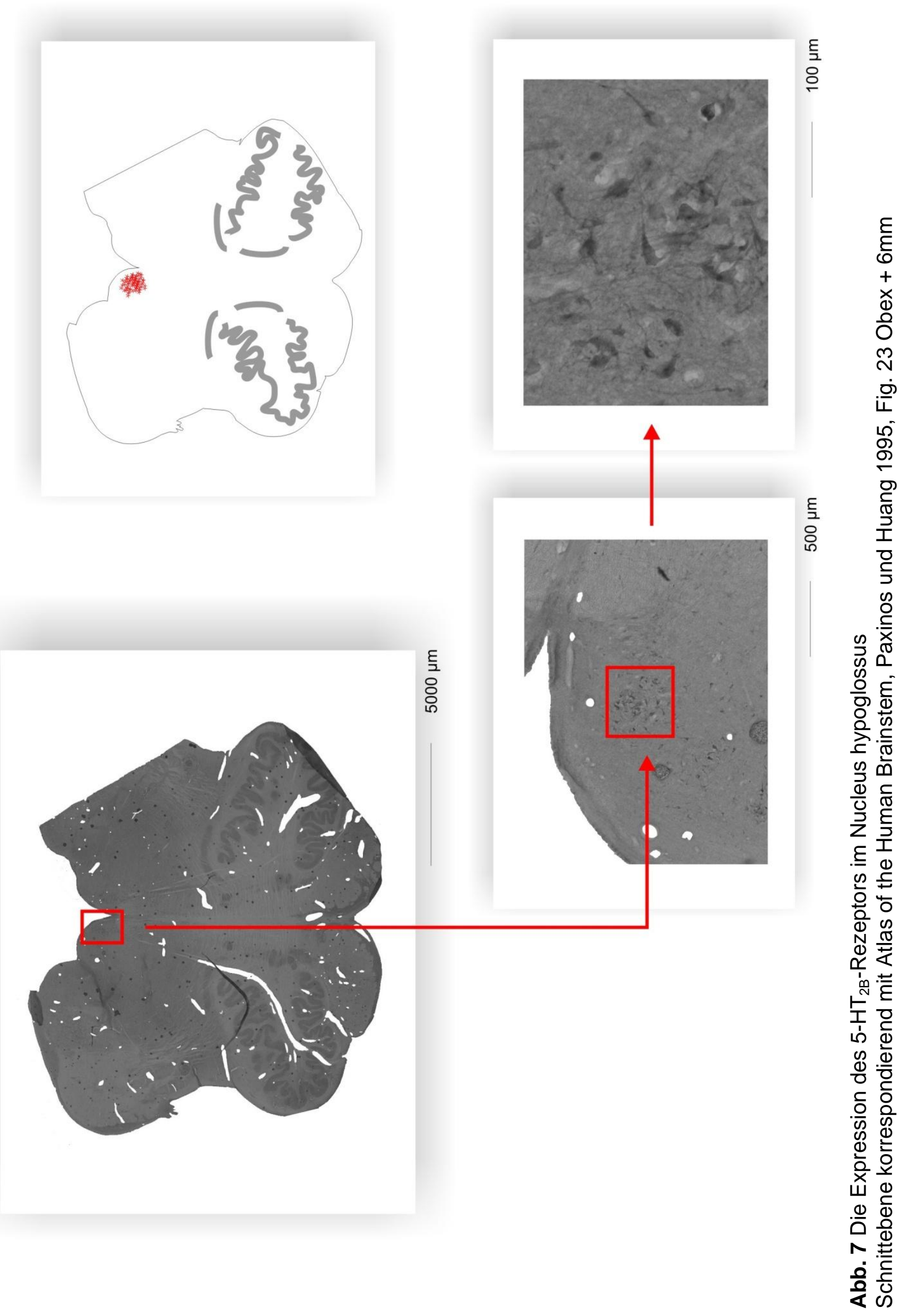



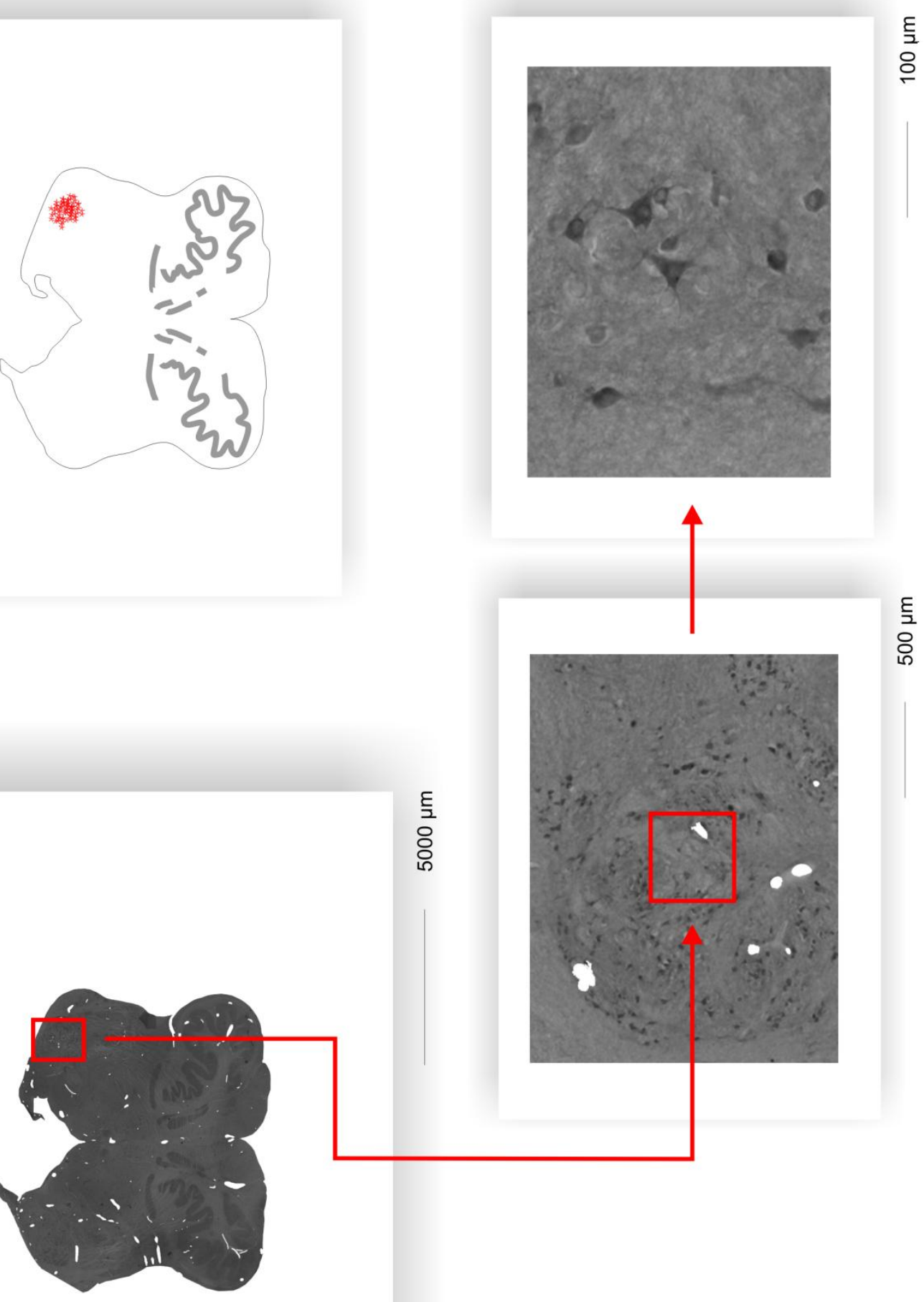

톡

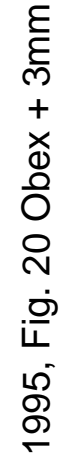

통

ํㅗㄴ

읃

ำ

ชิ

ल

(1)

ป气

ก

을 돌

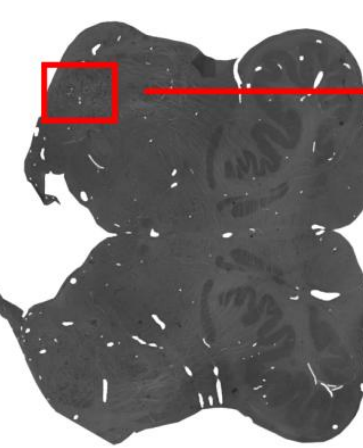

क

은

원 은

过

品

도을

เก

Ф $\frac{\Phi}{0}$

드 응

क क

क

흔우

爻

()

$\infty \stackrel{0}{\infty}$

安害 


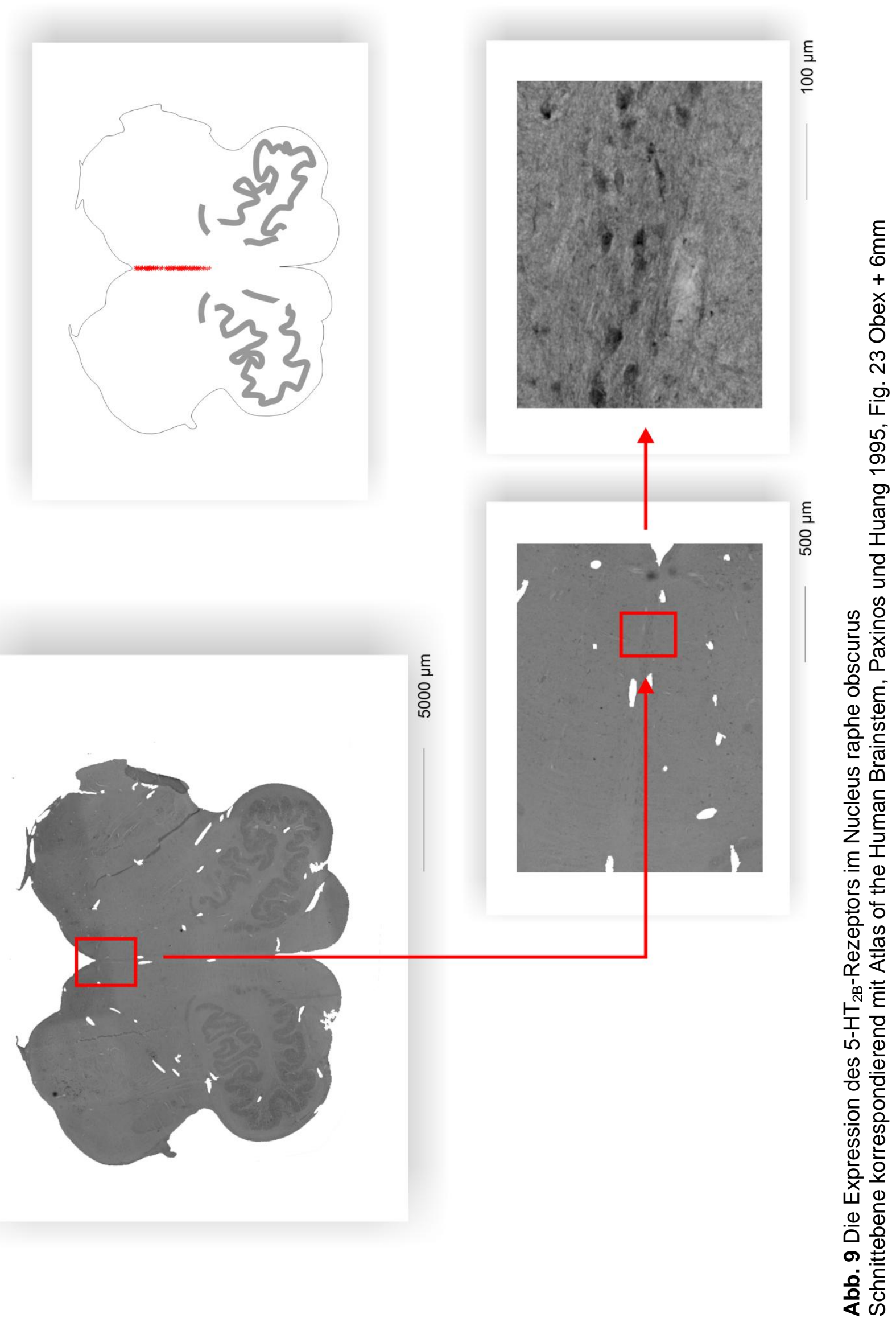




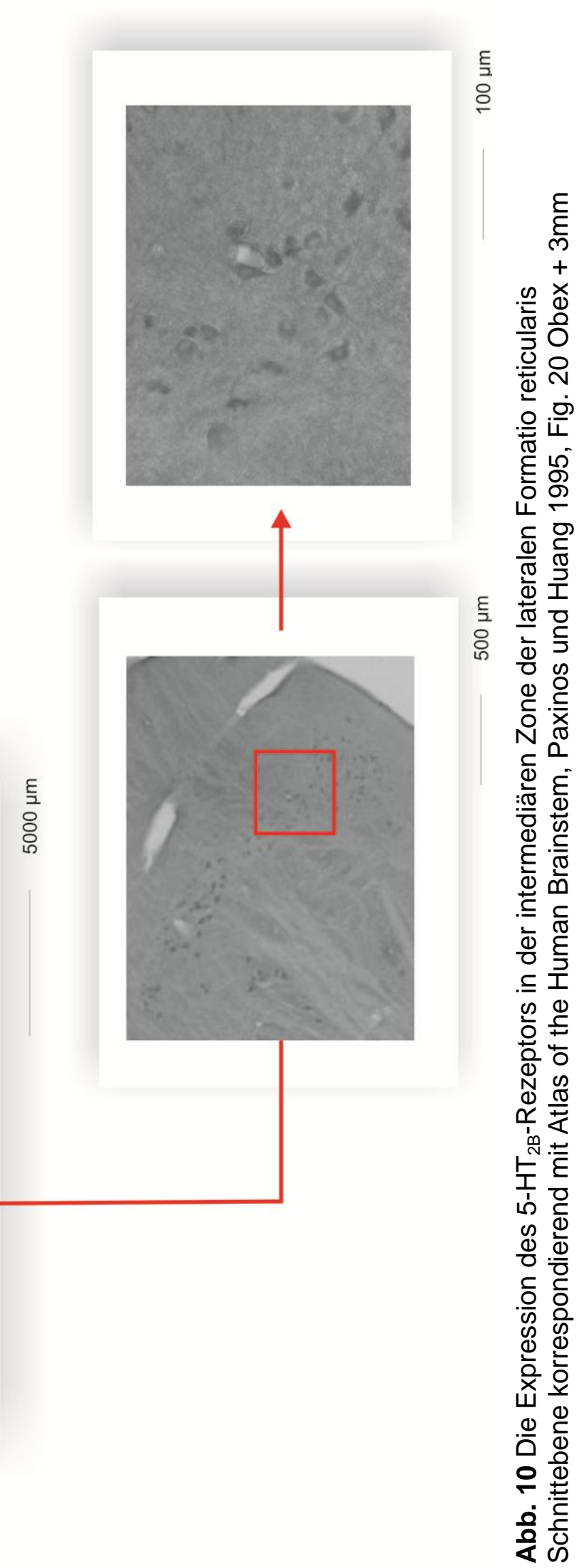




\subsection{Analyse der Zellzahl und Zelldichte mit Hilfe des Coolscopes}

\subsubsection{Fälle Plötzlichen Kindstodes (SIDS IA) im Vergleich mit der Kontrollgruppe}

Zusammenfassend ergab sich eine tendenziell geringere Zahl und Dichte an $5-\mathrm{HT}_{2 \mathrm{~B}^{-}}$ rezeptortragenden Zellen im Nucleus hypoglossus, Nucleus cuneatus externus und Nucleus raphe obscurus bei den Proben, die dem Plötzlichen Kindstod (SIDS IA) zugeordnet wurden, im Vergleich mit der Kontrollgruppe. Im Gegensatz zu den anderen Kerngebieten war die Dichte und Anzahl der $5-\mathrm{HT}_{2 \mathrm{~B}}$-rezeptortragende Zellen in der lateralen retikulären Formation in den Proben des Plötzlichen Kindstodes (SIDS IA) etwas höher als in der Kontrollgruppe (Abbildung 11).

Ein signifikanter Unterschied in der Zahl und Dichte der 5- $\mathrm{HT}_{2 \mathrm{~B}}$-rezeptortragenden Zellen des Nucleus hypoglossus bestand zwischen den Proben, die dem Plötzlichen Kindstod (SIDS IA) zugeordnet wurden und den Proben der Kontrollgruppe $p=0,02$. Die Proben der Gruppe SIDS IA hatten mit einer durchschnittlichen Zellzahl von 34,91 \pm 1,94 5- $\mathrm{HT}_{2 \mathrm{~B}}$-rezeptortragenden Zellen im Nucleus hypoglossus auf einer Fläche von $0,009 \mathrm{~cm}^{2}$ eine deutlich geringere Zelldichte gegenüber den Proben der Kontrollgruppe mit einer durchschnittlichen Zellzahl von 50,20 \pm 9,50 Zellen. Somit ist die Dichte der 5$\mathrm{HT}_{2 \mathrm{~B}}$-rezeptortragenden Zellen im Nucleus hypoglossus der dem Plötzlichen Kindstod zugeordneten Proben signifikant geringer als die der Kontrollen. Damit kann man bei den Fällen des Plötzlichen Kindstodes von einer Hypoplasie des Nucleus hypoglossus sprechen (Abbildung 12). 


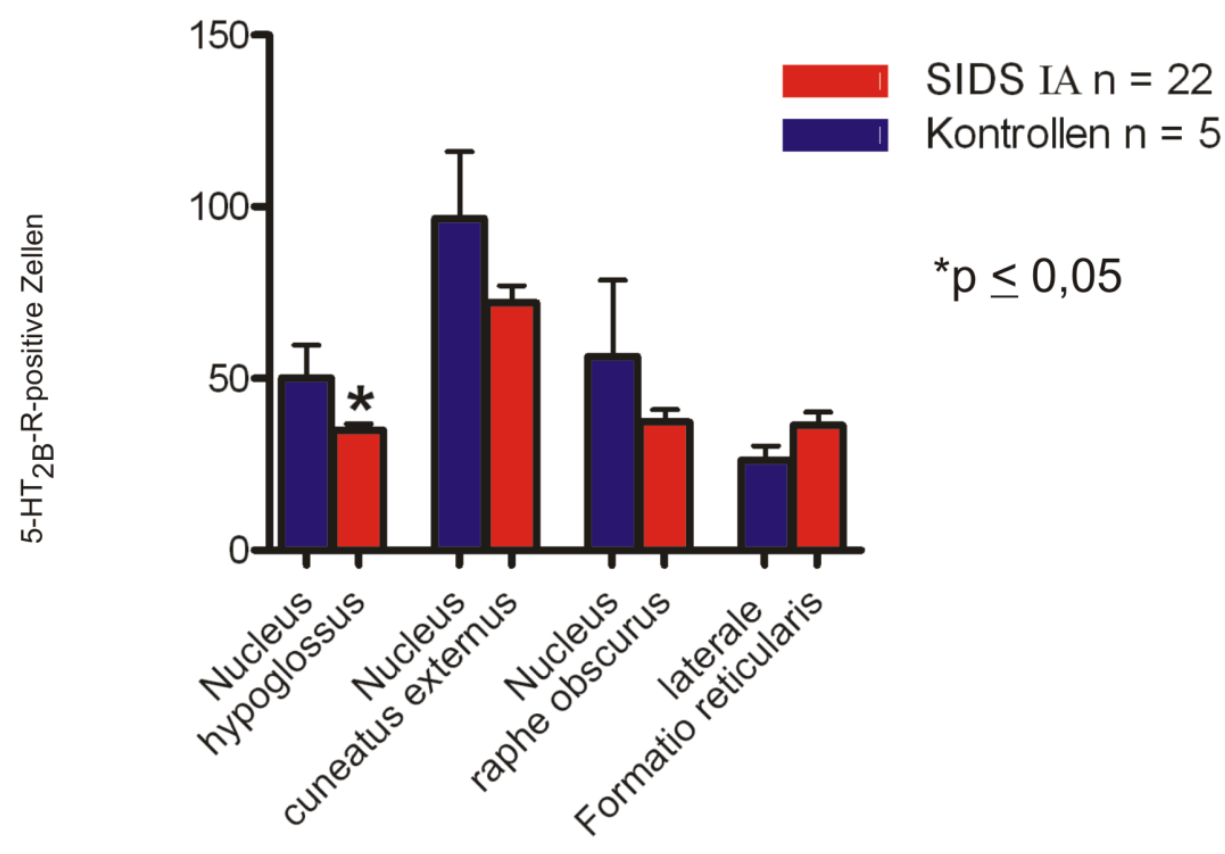

Abb.11 Expression des 5- $\mathrm{HT}_{2 \mathrm{~B}}-$ Rezeptors

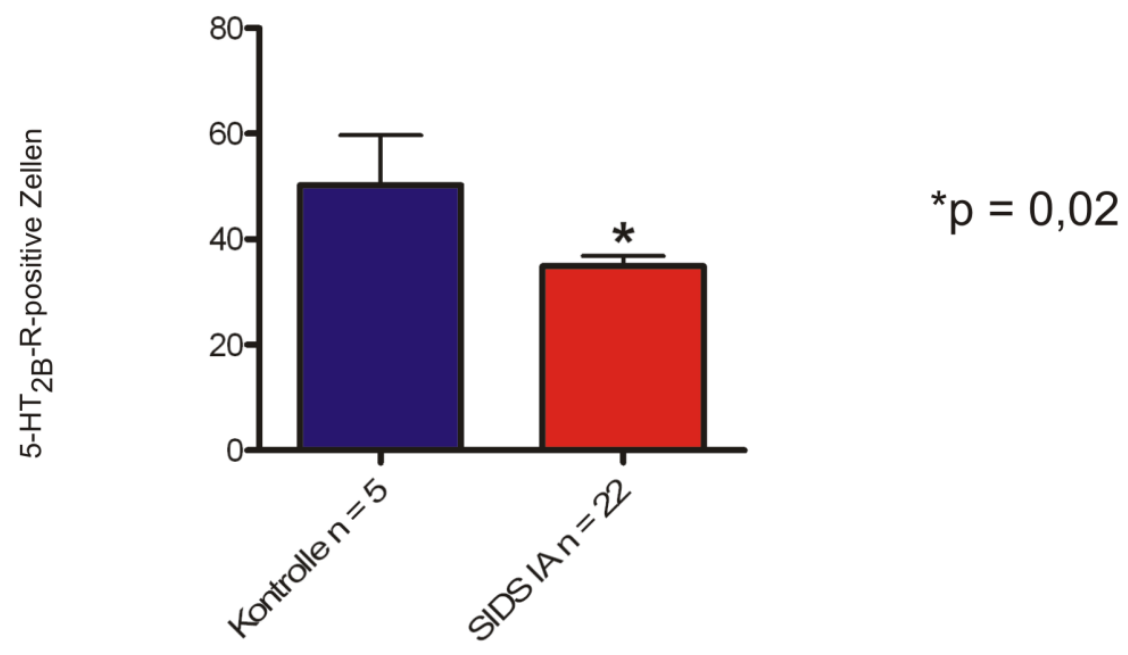

$50.20 \pm 9,50 \quad 34.91 \pm 1,94$

Abb. 12 Expression des 5- $\mathrm{HT}_{2 \mathrm{~B}}$-Rezeptors im Nucleus hypoglossus.

Angaben: Mittelwert \pm Standardfehler, SIDS IA: untersuchte Gruppe aller Fälle Plötzlichen Kindstodes ohne Auffälligkeiten bei der Obduktion 


\subsubsection{Fälle Plötzlichen Kindstodes mit entzündlicher Komponente (SIDS II) im Vergleich mit der Kontrollgruppe}

Im Gegensatz zu den anderen Kerngebieten war die Dichte und Anzahl der $5-\mathrm{HT}_{2 \mathrm{~B}}{ }^{-}$ rezeptortragenden Zellen in der lateralen retikulären Formation in den Proben des Plötzlichen Kindstodes (SIDS IA) etwas höher als in der Kontrollgruppe (Abbildung 11). Im Vergleich der Kontrollgruppe mit Proben des Plötzlichen Kindstodes mit entzündlicher Komponente (SIDS II) wird dieser Unterschied signifikant $p=0,03$ (Abbildung 13). Die Proben der Gruppe SIDS II hatten mit einer durchschnittlichen Zellzahl von $48,08 \pm 5,485-\mathrm{HT}_{2 \mathrm{~B}}$-rezeptortragenden Zellen in der lateralen retikulären Formation auf einer Fläche von $0,139 \mathrm{~cm}^{2}$ eine deutlich höhere Zelldichte gegenüber den Proben der Kontrollgruppe mit einer durchschnittlichen Zellzahl von 26,20 \pm 4,26 Zellen (Abbildung 14). 


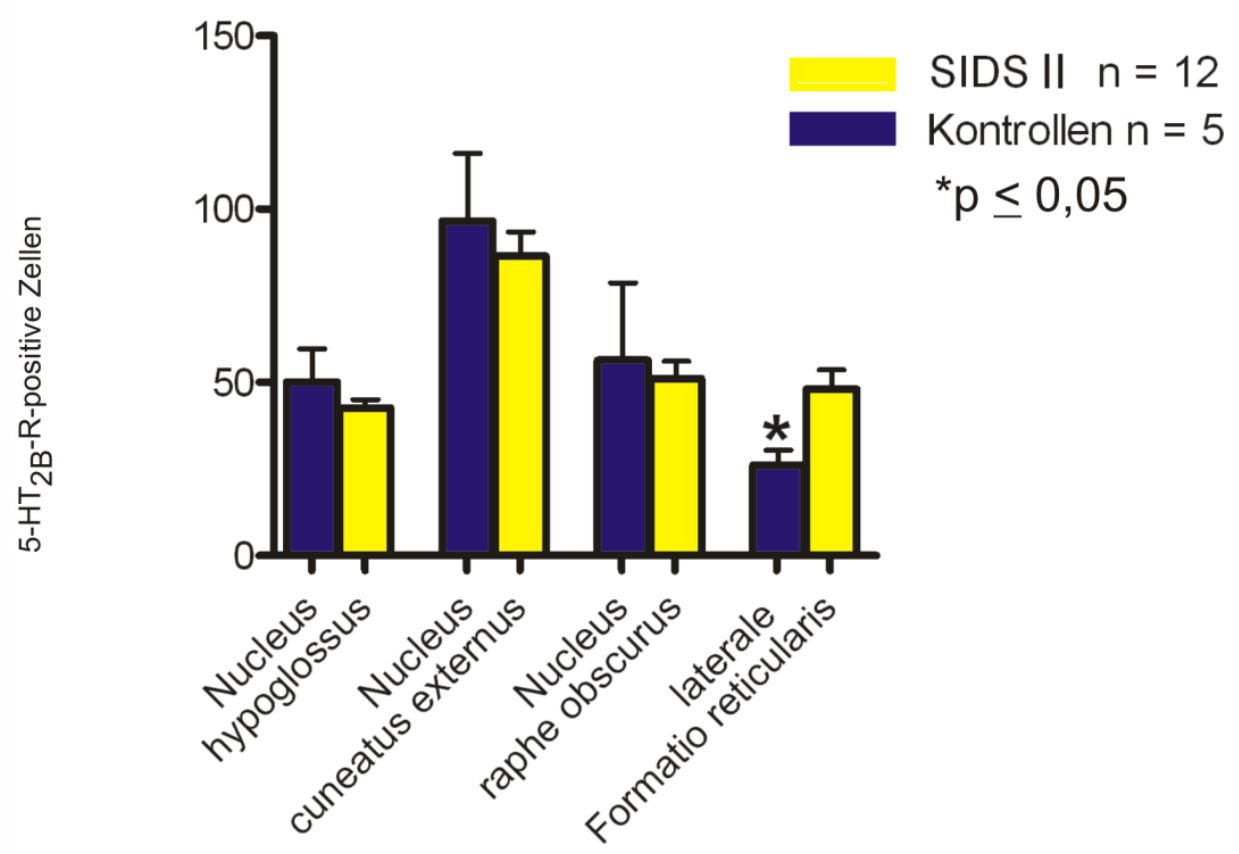

Abb.13 Expression des 5- $\mathrm{HT}_{2 \mathrm{~B}}$-Rezeptors

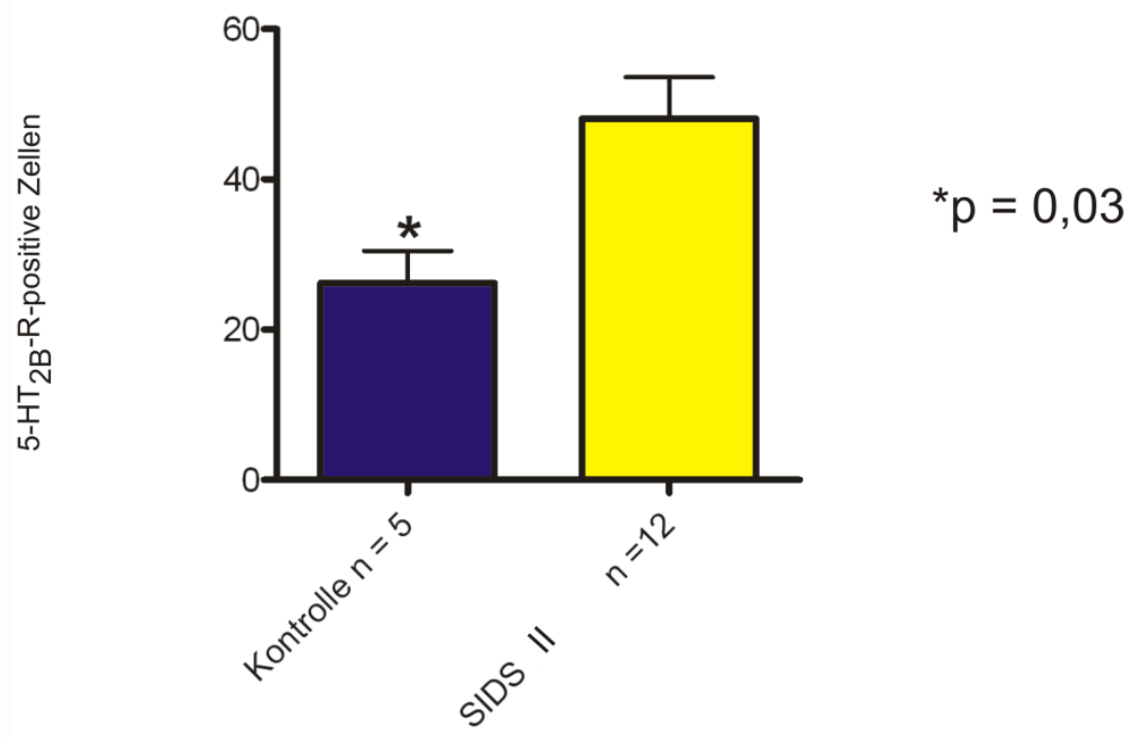

$26,20 \pm 4,26 \quad 48,08 \pm 5,48$

Abb. 14 Expression des 5- $\mathrm{HT}_{2 \mathrm{~B}}$-Rezeptors in der lateralen Formatio reticularis. Angaben: Mittelwert \pm Standardfehler, SIDS II: untersuchte Gruppe aller Fälle Plötzlichen Kindstodes mit Zeichen einer milden Entzündung 


\subsubsection{Fälle Plötzlichen Kindstodes (SIDS IA + SIDS II) im Vergleich mit der Kontrollgruppe}

Werden die Proben der Fälle des Plötzlichen Kindstodes mit und ohne entzündlicher Komponente (SIDS IA + SIDS II) zusammengefasst und mit der Kontrollgruppe verglichen, kann kein signifikanter Unterschied in der Zellzahl in der lateralen Formatio retikularis gefunden werden (Abbildung 15).

Allerdings bestätigt sich die Hypoplasie des Nucleus hypoglossus auch, wenn die Proben der Fälle des Plötzlichen Kindstodes mit und ohne entzündlicher Komponente (SIDS IA + SIDS II) zusammengefasst und mit der Kontrollgruppe verglichen werden $p=$ 0,03 (Abbildung 16). Für die Proben der Gruppe SIDS IA + SIDS II ergibt sich eine durchschnittliche Zellzahl von 37,65 $\pm 1,625-\mathrm{HT}_{2 \mathrm{~B}}$-rezeptortragenden Zellen im Nucleus hypoglossus auf einer Fläche von $0,009 \mathrm{~cm}^{2}$ gegenüber den Proben der Kontrollgruppe mit einer durchschnittlichen Zellzahl von 50,20 \pm 9,50 Zellen. Somit ist die Dichte der 5$\mathrm{HT}_{2 \mathrm{~B}}$-rezeptortragenden Zellen im Nucleus hypoglossus der dem Plötzlichen Kindstod (SIDS IA + SIDS II) zugeordneten Proben signifikant geringer als die der Kontrollen. 


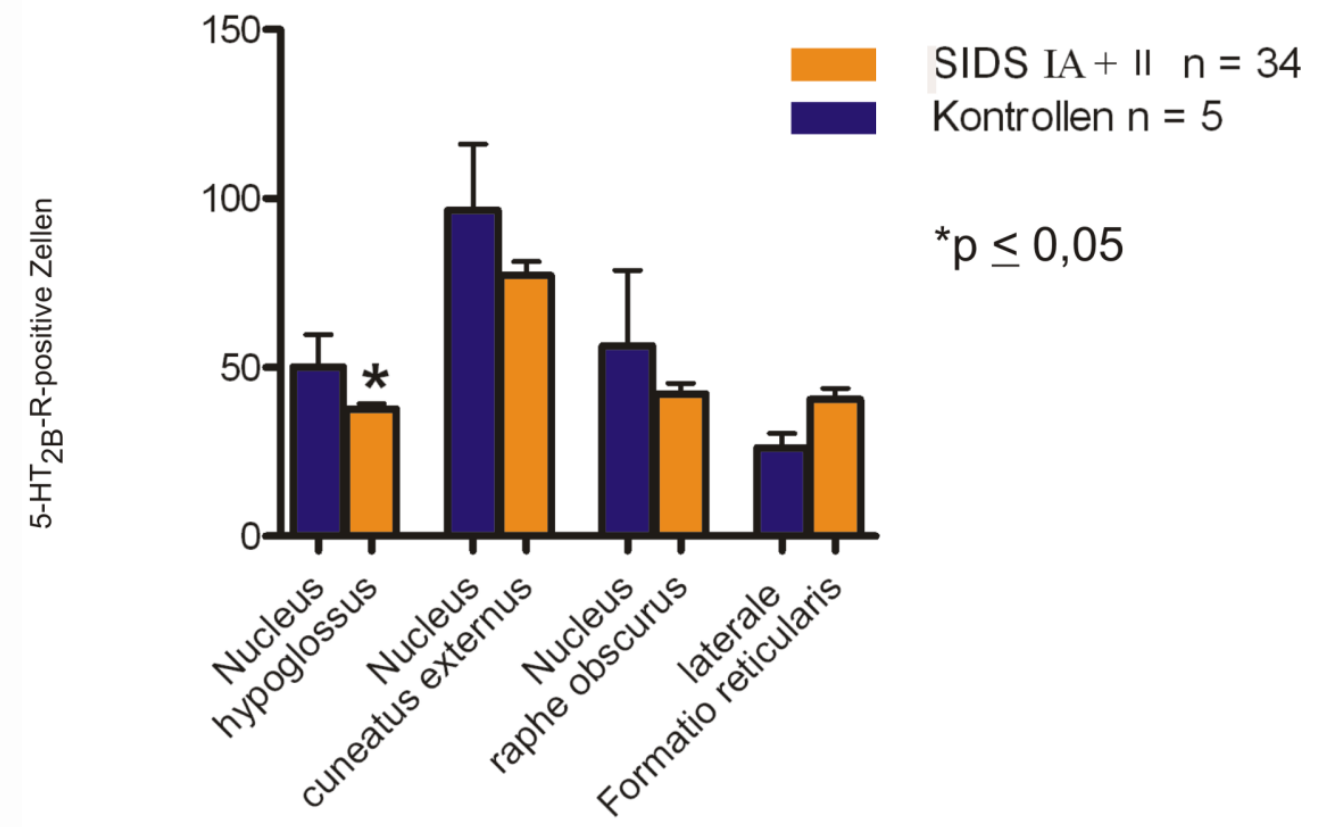

Abb.15 Expression des 5- $\mathrm{HT}_{2 \mathrm{~B}}$-Rezeptors in Kernen der Medulla oblongata

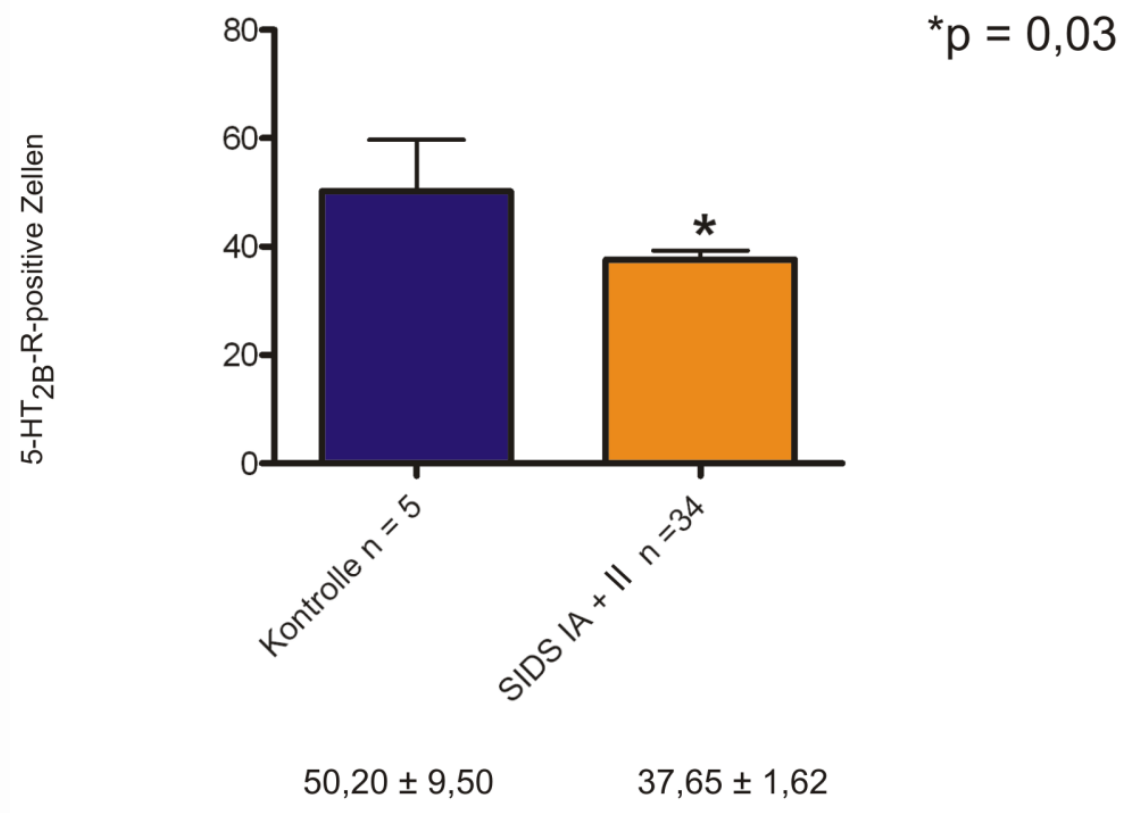

Abb. 16 Expression des 5- $\mathrm{HT}_{2 \mathrm{~B}}$-Rezeptors im Nucleus hypoglossus.

Angaben: Mittelwert \pm Standardfehler, SIDS IA: untersuchte Gruppe aller Fälle Plötzlichen Kindstodes ohne Auffälligkeiten bei der Obduktion, SIDS II: untersuchte Gruppe aller Fälle Plötzlichen Kindstodes mit Zeichen einer milden Entzündung 


\subsection{Graphische Zusammenfassung der Resultate}

Die Hypoplasie des Nucleus hypoglossus bei Fällen Plötzlichen Kindstodes ist die Kernaussage dieser Arbeit. Fälle Plötzlichen Kindstodes (SIDS IA) hatten eine deutlich geringere Zahl $5-\mathrm{HT}_{2 \mathrm{~B}}$-rezeptortragender Zellen im Nucleus hypoglossus im Vergleich zu Kontrollen $p=0,02$. Auch beim Vergleich aller untersuchten Fälle Plötzlichen Kindstodes (SIDS IA + SIDS II) ergab sich eine signifikant geringere Zahl $5-\mathrm{HT}_{2 \mathrm{~B}^{-}}$ rezeptortragender Zellen im Nucleus hypoglossus im Vergleich zu Kontrollen $p=0,03$.

Diese Hypoplasie des Nucleus hypoglossus in den Fällen Plötzlichen Kindstodes zeigt Abbildung 17. Die normale Struktur des Kerngebiets wird der hypoplastischen gegenübergestellt.

Im Unterschied zu den anderen Kerngebieten war die Dichte und Anzahl der 5- $\mathrm{HT}_{2 \mathrm{~B}^{-}}$ rezeptortragenden Zellen in der lateralen retikulären Formation in den Proben des Plötzlichen Kindstodes mit entzündlicher Komponente (SIDS II) signifikant höher als in der Kontrollgruppe $p=0,03$. Diese höhere Zellzahl und Dichte in Fällen Plötzlichen Kindstodes mit entzündlicher Komponente zeigt Abbildung 18. 

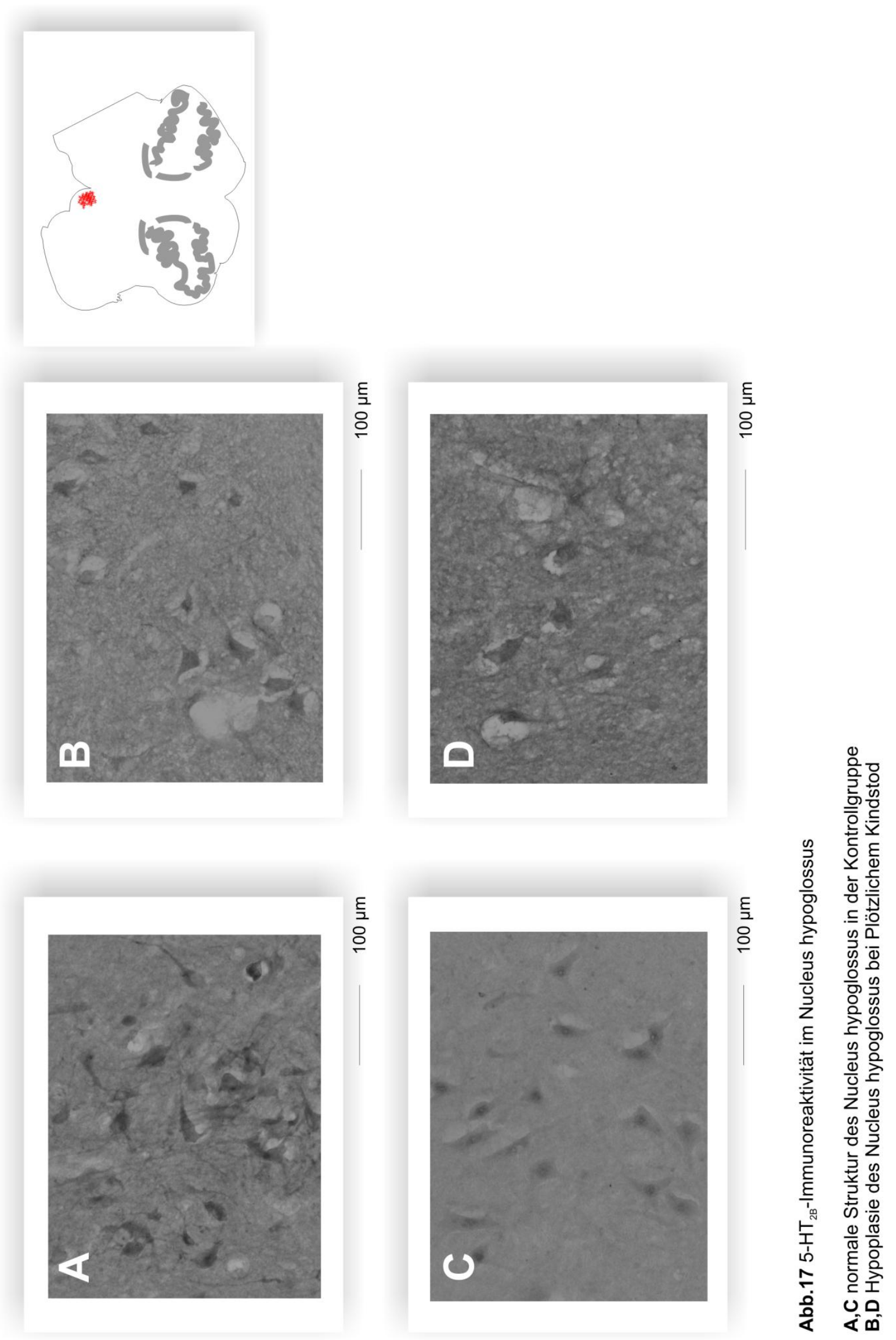


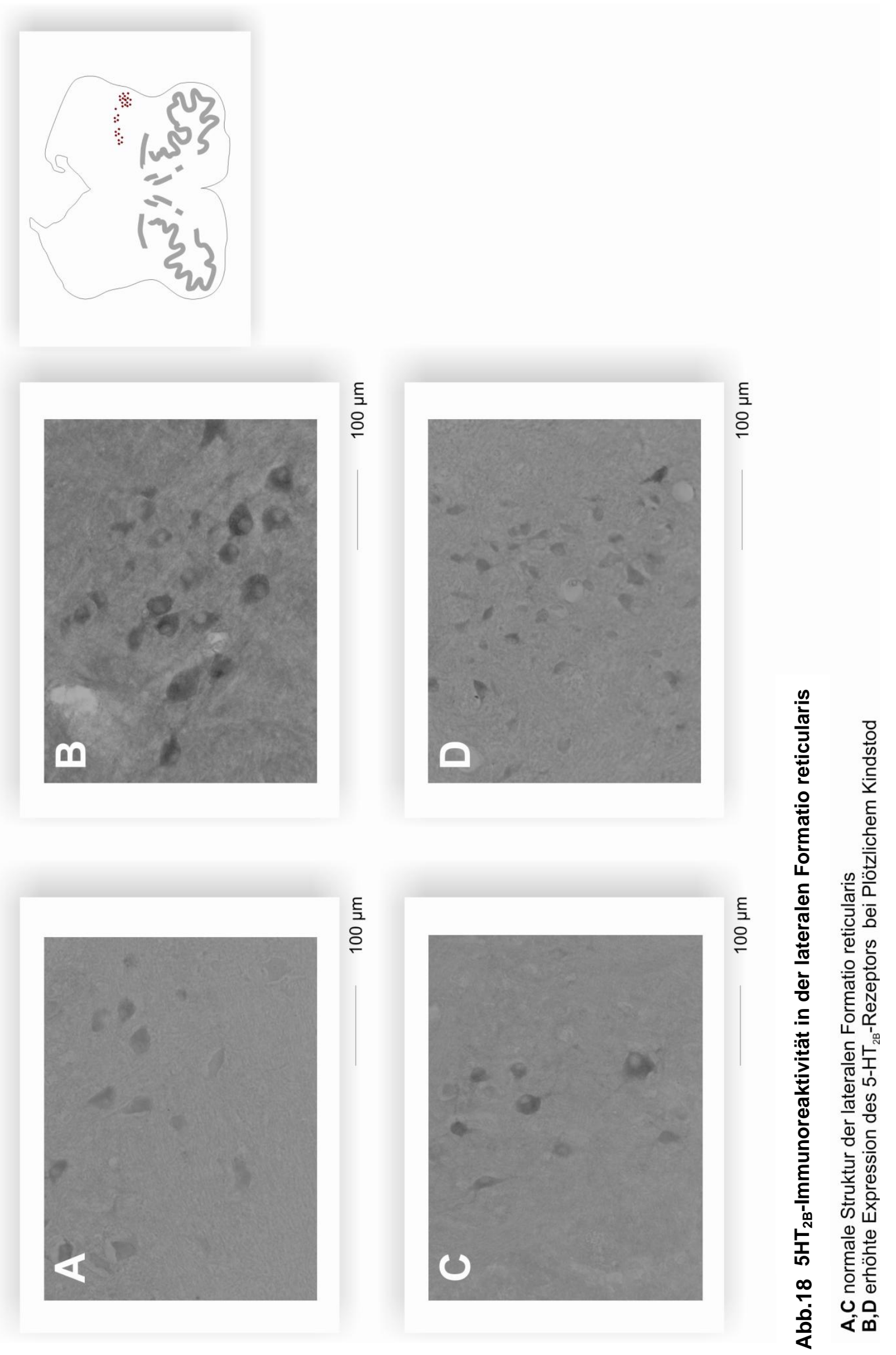




\section{Diskussion}

\subsection{Interpretation der Ergebnisse}

Die niedrigere Zellzahl und Dichte im Nucleus hypoglossus im Hirnstamm, der an Plötzlichem Kindstod verstorbenen Säuglinge, im Vergleich mit Hirnstämmen, der an anderen Diagnosen verstorbenen Säuglinge, unterstützt die Bedeutung und das Vorhandensein einer Pathologie im serotonergen System beim Plötzlichen Kindstod.

Der Nucleus hypoglossus moduliert die Durchgängigkeit der oberen Atemwege und somit auch die Sauerstoffzufuhr durch die Kontrolle der Zungenmotorik. Die geminderte Anzahl 5- $\mathrm{HT}_{2 \mathrm{~B}}$-rezeptortragender Zellen kann sowohl ein Entwicklungsdefizit, das mit vermindertem 5- $\mathrm{HT}_{2 \mathrm{~B}}$-Rezeptorbesatz einhergeht, als auch eine Hypoplasie serotonerger Neurone anderer Genese widerspiegeln. Die Hypoplasie dieses Kerns in Säuglingen, die an Plötzlichem Kindstod sterben, lässt eine Funktionsminderung der Zungenmotorik vermuten.

In Zusammenschau mit tierexperimentellen Daten (Manzke et al. 2005a,b) kann eine verminderte Anzahl 5- $\mathrm{HT}_{2 \mathrm{~B}}$-rezeptortragender Zellen funktionell eine gestörte Atemfrequenzregulation bedeuten, was eine insuffiziente Schnappatmung erklären kann.

Die vergleichbaren Zellzahlen und Dichten im Nucleus cuneatus externus und im Nucleus raphe obscurus bedeuten keinesfalls ein Nichtvorhandensein einer Pathologie im serotonergen System dieser Kerne überhaupt. Vielmehr ist dort gerade nur die 
Anzahl der $5-\mathrm{HT}_{2 \mathrm{~B}}-$ rezeptortragenden Zellen nicht gestört. Andere Studien beschreiben auch eine geminderte Anzahl serotonerger Neurone in Kernen der Raphe (Lavezzi et al. 2009). Über deren Besatz mit 5- $\mathrm{HT}_{2 \mathrm{~B}}$-Rezeptoren existieren allerdings noch keine Daten. Geht man davon aus, dass im Hirnstamm an Plötzlichem Kindstod verstorbener Säuglinge weniger serotonerge Neurone existieren, könnten die noch vorhandenen Zellen kompensatorisch mehr $5-\mathrm{HT}_{2 \mathrm{~B}}$-Rezeptoren exprimieren, so dass bei einer reinen 5- $\mathrm{HT}_{2 \mathrm{~B}}$-Rezeptordarstellung ein Unterschied in der Zellzahl nicht auffällt.

Die höhere Zellzahl in der lateralen Formatio retikularis bei Fällen Plötzlichen Kindstodes mit entzündlicher Komponente im Vergleich zur Kontrollgruppe könnte ein Hinweis auf eine Hochregulierung der Expression des $5-\mathrm{HT}_{2 \mathrm{~B}}-$ Rezeptors im Rahmen von Adaptationsvorgängen bei Entzündung sein. Die erhöhte Expression des $5-\mathrm{HT}_{2 \mathrm{~B}^{-}}$ Rezeptors könnte über Proteinkinasesignalwege ähnlich dem der stress-aktiviertenProteinkinase (SAPK) verlaufen (de Nadal und Posas 2010; Tibbles und Woodgett 1999). Bei dieser Signalkaskade führen Cytokine im Rahmen einer Entzündung zur Aktivierung der SAPK und somit zur Modifikation zellulärer Genexpression (de Nadal und Posas 2010; Tibbles und Woodgett 1999).

Die vermehrte Expression des $5-\mathrm{HT}_{2 \mathrm{~B}}$-Rezeptors in der lateralen Formatio retikularis könnte funktionell zur Feinjustierung des respiratorischen Netzwerkes dienen und so zu einer Stabilisierung der Atmungsregulation und homöostatischer Funktionen beitragen. 


\subsection{Vergleich mit anderen Autoren: Serotonin und respiratorische Disregulation}

Obwohl makroskopisch keine Pathologien an Hirnstämmen von an Plötzlichem Kindstod verstorbener Säuglinge zu erkennen sind, haben zahlreiche Studien Auffälligkeiten auf zellulärer und genetischer Ebene ergeben. Dabei rückt das serotonerge System in den Vordergrund, das durch Interaktion mit anderen Neurotransmittern, autonome Reaktionen auf homöostatische Stressoren moduliert. Diese autonome Kontrolle ist durch ein insuffizientes serotonerges System bei Säuglingen, die an Plötzlichem Kindstod versterben, gestört.

Korrespondierend zu den Ergebnissen dieser Arbeit, die eine reduzierte Dichte des Serotoninrezeptorsubtyps 2B im Nucleus hypoglossus nachweist, zeigt eine immunhistochemische Studie aus den USA eine deutlich reduzierte Bindung an 5- $\mathrm{HT}_{1 \mathrm{~A}}-$ Rezeptoren in verschiedenen Kernen der Medulla oblongata bei SIDS. Trotz erhöhter serotonerger Zellzahl in den Nuclei raphe obscurus, gigantocelularis, paragigantocellularis lateralis und arcuatus ist die $5-\mathrm{HT}_{1 \mathrm{~A}}-$ Rezeptoranzahl vermindert . Auch die Anzahl der Serotonintransporter ist im Vergleich zur Gesamtzahl serotonerger Neurone bei Plötzlichem Kindstod erniedrigt. Außerdem weisen die serotonergen Neurone der Plötzlichen Kindstodes-Fälle morphologisch ein Entwicklungsdefizit auf, es kommen proportional mehr granuläre Zellen vor. In den Kontrollfällen wurden mehr multipolare Zellen gesehen (Paterson et al. 2006). Neben der geminderten Anzahl an Serotoninrezeptoren konnte im Gewebe, der an Plötzlichem Kindstod verstorbenen Säuglinge auch weniger Serotonin und geringere Mengen an Tryptophanhydroxylase isoliert werden (Duncan et al. 2010). Daten über den $5-\mathrm{HT}_{2 \mathrm{~B}}-$ Rezeptorbesatz sind in der Literatur bisher nicht beschrieben. 
Der Versuch, Polymorphismen im 5- $\mathrm{HT}_{2 \mathrm{~A}}$-Rezeptor-gen mit SIDS zu assoziieren, blieb bisher erfolglos (Rand et al. 2009).

Vor der Annahme einer respiratorischen Disregulation, die sowohl von einer Störung der Atmungsregulation bei Hypoxie als auch von einer gestörten Arousalreaktion ausgeht, wurde der Atemrhythmusgenerator, der Prä-Bötzinger Komplex, näher untersucht. Im Zusammenhang mit dem Plötzlichen Kindstod wurde vor kurzem in einer Studie die Zytoarchitektur und Anatomie des Prä-Bötzinger Komplexes identifiziert. Es gelang dabei zum ersten Mal, an humanem Gewebe die genaue Lokalisation des Prä-Bötzinger Komplexes zu beschreiben. Beim Vergleich der Zellstruktur im Prä-Bötzinger Komplex von Plötzlichen Kindstodes-Fällen im Vergleich zu Kontrollen fiel eine Hypoplasie des Atemrythmusgenerators auf, sowie eine verminderte Anzahl an Dendriten (Lavezzi und Matturri 2008).

Die Hypoplasie verschiedener Kerngebiete der Medulla oblongata zieht sich wie ein roter Faden durch die einzelnen Studienergebnisse.

Die Verknüpfung zwischen Serotonin und Atmung ist im Tiermodell in großen Teilen gezeigt. So werden bei transgenen Mäusen, denen serotonerge Neurone fehlen, respiratorische Defizite mit schweren Apnoephasen, die vor allem in der Neonatalperiode auftreten, beobachtet (Hodges et al. 2009). Auf die Verbindung von Serotonin und Atmung weist auch ein Risikofaktor für den Plötzlichen Kindstod hin. Opiatkonsum in der Schwangerschaft erhöht das Risiko des Säuglings für den Plötzlichen Kindstod erheblich. Im Tiermodell konnte gezeigt werden, dass die Aktivierung des $5-\mathrm{HT}_{4 \mathrm{~A}}-$ Rezeptors eine Opiat induzierte Atemdepression aufheben kann (Manzke et al. 2003). 
Auch auf genetischer Ebene konnte eine Studie den Plötzlichen Kindstod mit Polymorphismen im Serotonintransporter-gen in Verbindung bringen (Weese-Mayer et al. 2003).

Darüberhinaus wurden Polymorphismen in Genen (z.B. PHOX2B) mit Bedeutung für die Entwicklung serotoninerger und noradrenalinerger Neurone mit dem Plötzlichen Kindstod assoziiert (Weese-Mayer et al. 2007).

\subsection{Hirnstammpathologien in anderen Neurotransmittersystemen}

Einen weiteren Hinweis auf Hirnstammpathologien in Neurotransmittersystemen, die mit Serotonin interagieren, lieferte ein vor kurzem mit dem Plötzlichen Kindstod assoziierter funktionaler Polymorphismus im Tyrosinhydroxylase-gen, das die Produktion von Noradrenalin in Neuronen reguliert (Klintschar et al. 2008). Im Nucleus dorsalis nervi vagi und in der ventrolateralen Medulla wurden weniger Tyrosinhydroxylase-positive Zellen beim Plötzlichen Kindstod beschrieben (Obonai et al. 1998).

Immunhistochemisch ergab eine Studie aus Australien bei Autopsiefällen Plötzlichen Kindstodes eine verminderte Anzahl und Dichte von Neuronen, die Acetylcholintransferase enthielten, im Nucleus hypoglossus und im Nucleus dorsalis nervi vagi (Mallard et al 1999). Auch muskarinerge Acetylcholinrezeptoren waren im Nucleus arcuatus in geringerer Anzahl bei Fällen Plötzlichen Kindstodes enthalten, als bei Kontrollen (Kubo et al. 1998).

Desweiteren zeigte die Untersuchung der Expression des NMDA-Rezeptors vom Subtyp 1 eine erhöhte mRNA in sechs Kernen der Medulla oblongata, im Nucleus dorsalis nervi 
vagi wurde bei SIDS mehr NMDA-Rezeptor1-Protein, im Nucleus spinalis nervi trigemini dagegen weniger gefunden als bei Kontrollen (Machaalani und Walters 2003).

\section{Zusammenfassung}

Der Plötzliche Kindstod ist die häufigste Todesursache von Säuglingen im Alter zwischen 1 Monat und 1 Jahr (Hunt und Hauck 2006). Diese Arbeit unterstützt die Hypothese des Modells des fatalen Dreiecks, das den Plötzlichen Kindstod als fehlerhafte Hirnstammreaktion auf Hypoxie während einer kritischen Entwicklungsperiode des Säuglings ansieht (Kinney et al. 2009a). Klinische Beobachtungen beschreiben kardiorespiratorische und Arousal- Defizite bei Fällen Plötzlichen Kindstodes. Schon vor dem Tod der Säuglinge waren vermehrt Apnoephasen, geringere kortikale Aktivität und Pulsdefizite aufgetreten (Kato et al. 2003, Sridhar et al. 2003). Diese homöostatische Disregulation lässt sich verknüpfen mit neuropathologischen Daten, die veränderte Anzahlen serotonerger Neurone, Transporter und Rezeptoren beinhalten.

Ausgehend von der Annahme, dass mangelnde homöostatische Kontrolle auf einer Hirnstammpathologie des serotonergen Systems beruht, wurden deshalb in dieser Arbeit Hirnstämme von Säuglingen, die an Plötzlichem Kindstod verstarben, im Vergleich mit Hirnstämmen von Kontrollfällen immunhistochemisch untersucht. Antikörperfärbungen gegen den $5-\mathrm{HT}_{2 \mathrm{~B}}$-Rezeptor repräsentierten die Verteilung dieses Rezeptors in Kernen des Hirnstammes. Dabei wurden Zellen mit 5- $\mathrm{HT}_{2 \mathrm{~B}}$-Rezeptorbesatz im Nucleus cuneatus externus, Nucleus raphe obscurus, Nucleus hypoglossus und in 
der lateralen retikulären Formation detektiert. Im Vergleich mit den Kontrollfällen fiel bei den Fällen Plötzlichen Kindstodes eine verminderte Anzahl an 5- $\mathrm{HT}_{2 \mathrm{~B}}$-Rezeptortragenden Zellen im Nucleus hypoglossus auf. Diese Hypoplasie wird als Defizit des serotonergen Systems gedeutet, dessen Bedeutung in der Kontrolle homöostatischer Funktionen vor allem im respiratorischen Bereich von zahlreichen tierexperimentellen Studien unterstützt wird (Kubin und Volgin 2008; Lalley et al. 1994; Manzke et al. 2005a,b; Richter et al. 1997). Damit könnte das serotonerge System sowohl ein vielversprechender Angriffspunkt in der genetischen Risikoermittlung für den Plötzlichen Kindstod als auch ein Ansatz für eine pharmakologische Therapie werden. 


\section{Literaturverzeichnis}

Arnestad M, Crotti L, Rognum TO, Insolia R, Pedrazzini M, Ferrandi C, Vege A, Wang DW, Rhodes TE, George AL, Schwartz JR, Schwartz PJ (2007): Prevalence of Long-QT Syndrome Gen Variants in Sudden Infant Death Syndrome. Circulation 115, 361-367

Barnes NM, Sharp T (1999): A review of central 5-HT receptors and their function. Neuropharmacology $\underline{38}, 1083-1152$

Beckwith JB: Discussion of the terminology and definition of the sudden infant death syndrome. In: Bergman AB, Beckwith JB, Tay CG: Proceedings of the Second International Conference on Causes of Sudden Death in Infants. University of Washington Press, Seattle 1970, 14-22

Benninghoff A, Drenckhahn D: Anatomie. Band 2, 16. Auflage; Urban \& Fischer Verlag, München 2004, $356 f$

Berner NJ, Grahn Da, Heller HC (1999): 8-OH-DPAT-sensitive neurons in the nucleus raphe magnus modulate thermoregulatory output in rats. Brein Res. $\underline{831}$, $155-164$

Bibel, Altes und Neues Testament, Einheitsübersetzung, Herder Verlag, Freiburg im Breisgau 2002, 1. Könige 3; Vers 16-28, 335-336 
Callebert J, Esteve JM, Hervé P, Peoc'h K, Tournois C, Drouet L, Launay JM, Maroteaux L (2006): Evidence for a control of plasma serotonin levels by 5hydroxytryptamine(2B) receptors in mice. J Pharmacol Exp Ther 317, 724-731

Choi DS, Ward SJ, Messaddeq N, Launay JM, Maroteaux L (1997): 5-HT2B receptor-mediated serotonin morphogenetic functions in mouse cranial neural crest and myocardiac cells. Development $\underline{124}, 1745-1755$

Cornea-Hebert V, Riad M, Wu C, Singh SK, Descarries L (1999): Cellular and subcellular distribution of the serotonin 5-HT2A receptor in the central nervous system of adult rat. J Comp Neurol $\underline{409}, 187-209$

Darnall RA, Harris MB, Gill WH, Hoffman JM, Brown JW, Niblock MM (2005): Inhibition of serotonergic neurons in the nucleus paragigantocellularis lateralis fragments sleep and decreases rapid eye movement sleep in the piglet: implications for sudden infant death syndrome. J Neurosci $\underline{25}, 8322-8332$

de Nadal E, Posas F (2010): Multilayered control of gene expression by stressactivated protein kinases. EMBO J $\underline{29}, 4-13$

Duncan JR, Paterson DS, Hoffman JM, Mokler DF, Borenstein NS, Belliveau RA, Krous HF, Haas EA, Stanley C, Nattie EE, Trachtenberg FL, Kinney HC (2010): Brainstem Serotonergic Deficiency in Sudden Infant Death Syndrome. JAMA 303, $430-437$ 
Duxon MS, Flanigan TP, Reavley AC, Baxter GS, Blackburn TP, Fone KCF (1997): Evidence for the expression of the $5-\mathrm{HT} 2 \mathrm{~B}$ receptor protein in the rat central nervous system. Neuroscience $\underline{76}, 323-329$

Egan C, Herrick-Davis K, Teitler M (1998): Creation of a constitutively activated state of the 5-HT2A receptor by site directed mutagenesis: revelation of inverse agonist activity of anatagonists. Ann N Y Acad Sci $\underline{861}, 136-139$

El-Khatib MF, Kiwan RA, Jamaleddine GW (2003): Buspirone treatment for apneustic breathing in brain stem infarct. Respir Care $\underline{48}, 956-958$

Filiano JJ, Kinney HC (1994): A perspective on neuropathologic findings in victims of the sudden infant death syndrome: the triple-risk model. Biol Neonate $\underline{65}, 194-197$

Garratt JC, Kidd EJ, Wright IK, Marsden CA (1991): Inhibition of 5-hydroxytryptamine neuronal activity by the 5-HT agonist, DOI. Eur J Pharmacol $\underline{199}$, 349-355

Guenther U, Manzke T, Wrigge H, Dutschmann M, Zinserling J, Putensen C, Hoeft A (2009): The counteraction of opioid-induced ventilatory depression by the serotonin 1A-agonist 8-OH-DPAT does not antagonize antinociception in rats in situ and in vivo. Anesth Analg $\underline{108}, 1169-1176$

Guntheroth WG, Spiers PS (2002): The triple risk hypotheses in sudden infant death syndrome. Pediatrics $\underline{110}$, e64 
Günther S, Maroteaux L, Schwarzacher SW (2006): Endogenous 5-HT2B receptor activation regulates neonatal respiratory activity in vitro. J Neurobiol $\underline{66}, 949-961$

Hamal Kr, Wideman RF, Anthony NB, Erf GF (2010): Differential expression of vasoactive mediators in microparticle-challenged lungs of chickens that differ in susceptibility to pulmonary arterial hypertension. Am J Physiol Integr Comp Physiol $\underline{298}, 235-242$

Hauck FR, Omojokun OO, Siadaty MS (2005): Do pacifiers reduce the risk of sudden infant death syndrome? A meta-analysis. Pediatrics $\underline{116}, 716-723$

Henderson LA, Keay KA, Bandler R (2000): Caudal midline medulla mediates behaviourally-coupled but not baroreceptor-mediated vasodepression. Neuroscience $\underline{98}, 779-792$

Hodges MR, Wehner M, Aungst J, Smith JC, Richerson GB (2009): Transgenic mice lacking serotonin neurons have severe apnea and high mortality during development. J Neurosci 로, 10341-10349

Hoyer D, Clarke DE, Fozard JR, Hartig PR, Martin GR, Mylecharane EJ, Saxena PR, Humphrey PP (1994): International Union of Pharmacology classification of receptors for 5-hydroxytryptamine (serotonin). Pharmacol Rev $\underline{46}, 157-193$

Hunt CE, Hauck FR (2006): Review Sudden infant death syndrome. Can Med Assoc $\mathrm{J} \underline{174}, 1861-1869$ 
Kato I, Franco P, Groswasser J, Scaillet S, Kelmanson I, Togari H, Kahn A (2003): Incomplete arousal processes in infants who were victims of sudden death. Am $\mathrm{J}$ Respir Crit Care Med 168, 1298-1303

Kennett GA, Lightowler S, de Biasi V, Stevens NC, Wood MD, Tulloch IF, Blackburn TP (1994): Effect of chronic administration of selective 5-hydroxytryptamine and noradrenaline uptake inhibitors on a putative index of 5-HT2C/2B receptor function. Neuropharmacology $\underline{33}, 1581-1588$

Kennett GA, Bailey F, Piper DC, Blackburn TP (1995): Effect of SB 200646A, a 5$\mathrm{HT} 2 \mathrm{C} / 5-\mathrm{HT} 2 \mathrm{~B}$ receptor antagonist, in two conflict models of anxiety.

Psychoparmacology $\underline{118}, 178-182$

Kennett GA, Wood MD, Bright F, Cilia J, Piper DC, Gager T, Thomas D, Baxter GS, Forbes IT, Ham P, Blackburn TP (1996): In vitro and in vivo profile of SB 206553, a potent $5-\mathrm{HT} 2 \mathrm{C} / 5-\mathrm{HT} 2 \mathrm{~B}$ receptor antagonist with anxiolytic-like properties. $\mathrm{Br} \mathrm{J}$ Pharmacol $\underline{117}, 427-434$

Kinney HC (2009): Neuropathology provides new insight in the pathogenesis of the sudden infant death syndrome. Acta neuropathol 117, 247-255

Kinney HC, Richerson GB, Dymecki SM, Darnall RA, Nattie EE (2009a): The brainstem and serotonin in the sudden infant death syndrome. Annu Rev Pathol $\underline{4}$, $517-550$ 
Kinney HC, Bradley T, Thach MD (2009b): The sudden infant death syndrome. N Engl J Med $\underline{361}, 795-805$

Klintschar M, Reichenpfader B, Saternus KS (2008): A functional polymorphism in the tyrosine hydroxylase gene indicates a role of noradrenalingergic signalling in sudden infant death syndrome (SIDS). Pediatrics $\underline{153}, 190-193$

Krous HF, Beckwith JB, Byard RW, Rognum TO, Bajanowski T, Corey T, Cutz E, Hanzlick R, Keens TG, Mitchell EA (2004): Sudden infant death syndrome and unclassified sudden infant deaths: a definitional and diagnostic approach. Pediatrics $\underline{114}, 234-238$

Kubin L, Volgin DV (2008): Developmental profiles of neurotransmitter receptors in respiratory motor nuclei. Repir Physiol Neurobiol 164, 64-71

Kubo S, Orihara Y, Gotohda T, Tokunada I, Tsuda R (1998): Immunohistochemical studies on neuronal changes in brain stem nucleus of forensic autopsied cases. II.

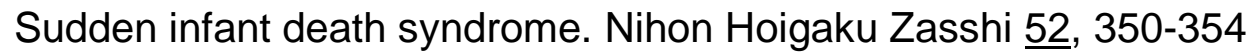

Lalley PM, Bischoff AM, Richter DW (1994): Serotonin 1A-receptor activation suppresses respiratory apneusis in the cat. Neurosci Lett $\underline{172}, 59-62$

Lavezzi AM, Matturri L (2008): Functional neuroanatomy of the human pre-Bötzinger complex with particular reference to sudden unexplained perinatal and infant death. Neuropathology $\underline{28}, 10-16$ 
Lavezzi AM, Casale V, Oneda R, Weese-Mayer DE, Matturri L (2009): Sudden infant death syndrome and sudden intrauterine unexplained death: Correlation between hypoplasia of raphé nuclei and serotonin transporter gene promoter polymorphism. Pediatr Res $\underline{66}, 22-27$

Löffler G, Petrides PE, Heinrich PC: Biochemie und Pathobiochemie. 8. Auflage; Springer Medizin Verlag, Heidelberg 2007, $1042 f$

Machaalani R, Waters KA (2003): NMDA receptor 1 expression in the brainstem of human infants and ist relevance tot he sudden infant death syndrome (SIDS). J Neuropathol Exp Neurol $\underline{62}, 1076-1085$

Machaalani R, Say M, Waters KA (2009): Serotonergic receptor $1 A$ in the sudden infant death syndrome brainstem medulla and associations with clinical risk factors. Acta Neuropathol $\underline{117}, 257-265$

Mallard C, Tolcos M, Leditschke J, Campbell P, Rees S (1999): Reduction in choline acetyltransferase immunoreactivity but not muscarinic-m2 receptor immunoreactivity in the brainstem of SIDS infants. J Neuropathol Exp Neurol $\underline{58}, 255-264$

Manzke T: Expression and function of serotonin receptor isoforms in the respiratory system. Med. Diss., Göttingen 2004

Manzke T, Günther U, Ponimanskin EG, Haller M, Dutschmann M, Schwarzacher S, Richter DW (2003): 5-HT4(a) receptors avert opioid-induced breathing depression without loss of analgesia. Science $\underline{301}, 226-229$ 
Manzke T, Günther U, Dutschmann M, Richter D (2005a): The role of 5-HT 1A, 2A, 2B and 7 receptor isoforms for recovery from opioid induced respiratory depression in rat. The Federation of American Societies for Experimental Biology, 19, 657

Manzke T, Kron M, Dutschmann M, Richter D (2005b): Expression patterns of 5$\mathrm{HT} 1 \mathrm{~A}, 2 \mathrm{~A}, 2 \mathrm{~B}, 4(\mathrm{a})$ and 7 receptor isoforms in the respiratory network of rat. The Federation of American Societies for Experimental Biology, 19, 657

Manzke T, Preusse S, Hülsmann S, Richter DW (2008): Developmental changes of serotonin receptor 4 (a) receptor expression in the rat pre-Bötzinger complex. J Comp Neurol $\underline{10}, 775-790$

Manzke T, Dutschmann M, Schlaf G, Mörschel M, Koch UR, Ponimanskin E, Bidon O, Lalley PM, Richter DW (2009): Serotonin targets inhibitory synapses to induce modulation of network functions. Philos Trans R Soc Lond B Biol Sci $\underline{364}, 2589-602$

Martin GR, Humphrey PP (1994): Receptors for 5-hydroxytryptamine: current perspectives on classification and nomenclature. Neuropharmacology $\underline{33}, 261-273$

McMahon LR, Cunningham KA (2001): Role of 5-HT(2a) and 5-HT(2B/2C) receptors in the behavioral interactions between serotonin and catecholamine reuptake inhibitors. Neuropsychopharmacology $\underline{24}, 319-329$

Messier ML, Li A, Nattie EE (2004): Inhibition of medullary raphe serotonergic neurons has age-dependent effects on the $\mathrm{CO} 2$ response in newborn piglets. J Appl Physiol. 96, 1909-1919 
Moon RY, Horne RSC, Hauck FR (2007): Sudden infant death syndrome. Lancet $\underline{370}, 1578-1587$

Narita N, Narita M, Takashima S, Nakayama M, Nagai T, Okado N (2001): Serotonin transporter gene variation is a risk factor for sudden infant death syndrome in the Japanese population. Pediatrics $\underline{107}, 690-692$

Nebigil CG, Hickel P, Messaddeq N, Vonesch JL, Douchet MP, Monassier L, György K, Matz R, Andriantsitohaina R, Manivet P, Launay JM, Maroteaux L (2001): Ablation of serotonin $5-\mathrm{HT}(2 \mathrm{~B})$ receptors in mice leads to abnormal cardiac structure and function. Circulation 103, 2973-2979

Obonai T, Yasuhara M, Nakamura T, Takashima S (1998): Catecholamine neurons alteration in the brainstem of sudden infant death syndrome victims. Pediatrics $\underline{101}$, 285-288

Opdal SH, Rognum TO (2004): The sudden infant death syndrome gene: does it exist?. Pediatrics $\underline{114}, 506-512$

Palacios JM, Waeber C, Hoyer D, Mengod G (1990), Distribution of serotonin receptors. Ann N Y Acad Sci $\underline{600}, 36-52$

Pasquale-Styles MA, Tackitt PL, Schmidt CJ (2007): Infant death scene investigation and the assessment of potential risk factors for asphyxia: a review of 209 sudden unexpected infant deaths. J Forensic Sci $\underline{52}$, 924-929 
Paterson DS, Trachtenberg FL, Thompson EG, Belliveau RA, Beggs AH, Darnall R, Chadwick AE, Krous HF, Kinney HC (2006): Multiple serotonergic brainstem abnormalities in sudden infant death syndrome. JAMA $\underline{296}, 2124-2132$

Paxinos G, Huang X: Atlas of the Human Brainstem; Academic Press, San Diego 1995

Poets CF (2004): Apparent life-threatening events and sudden infant death on a monitor. Pediatr Respir Rev $\underline{5}, 383-386$

Preuße S: Untersuchung der entwicklungsabhängigen Expression des Serotonin 4(a) Rezeptors im PräBötzinger Komplex der Ratte. Med. Diss., Göttingen 2005

Rand CM, Berry-Kravis EM, Fan W, Weese-Mayer DE (2009): HTR2A variation and sudden infant death syndrome: a case-control analysis. Acta Paediatr $\underline{98}, 58-61$

Rasch B, Friese M, Hofmann W, Naumann E: Quantitative Methoden 1. 2. Auflage; Springer-Verlag Gmbh, Berlin 2006

Rauser L, Savage JE, Meltzer HY, Roth BL (2001): Inverse agonist actions of typical and atypical antipsychotic drugs at the human 5-hydroxytryptamine(2C) receptor. $\mathrm{J}$ Pharmacol Exp Ther 299, 83-89

Richerson GB (2004): Serotonergic neurons as carbon dioxide sensors that maintain pH homeostasis. Nat Rev Neurosci $\underline{5}, 449-461$ 
Richter DW, Lalley PM, Pierrefiche O, Haji A, Bischoff AM, Wilken B, Hanefeld F (1997): Intracellular signal pathways controlling repiratory neurons. Respir Physiol $\underline{110}, 113-123$

Sinton CM, McCarley RW (2004): Neurophysiological mechanisms of sleep and wakefulness: a question of balance. Semin Neurol $\underline{24}, 211-223$

Sridhar R, Thach BT, Kelly DH, Henslee JA (2003): Characterization of successful and failed autoresuscitation in human infants including those dying of SIDS. Pediatr Pulmonol $\underline{36}, 113-122$

Statistisches Bundesamt: Todesursachen in Deutschland, Gestorbene in Deutschland an ausgewählten Todesursachen. Fachserie 12 Reihe 4, 44, Wiesbaden 2008

Stettner GM, Zanella S, Hilaire G, Dutschmann M (2008): 8-OH-DPAT suppresses spontaneous central apneas in the C57BL/6J mouse strain. Respir Physiol Neurobiol $\underline{161}, 10-15$

Tibbles LA, Woodgett JR (1999): The stress-activated protein kinase pahtways. Cell Mol Life Sci $\underline{55}, 1230-1254$

Tork I, Hornung JP: Raphé nuclei and the 5-HAT system; In: The Human Nervous System. Hrsg. Paxinos G, Academic, San Diego, 1990, 1001-1022 
Vege A, Ole Rognum T (2004): Sudden infant death syndrome, infection and inflammatory responses. FEMS Immunol Med Microbiol 42, 3-10

Vergé D, Calas A (2000): Serotoninergic neurons and serotonin receptors: gains from cytochemical approaches. J Chem Neuroanat $\underline{18}, 41-56$

Weese- Mayer DE, Zhlu L, Berry-Kravis EM, Maher BS, Silvestri JM, Marazita ML (2003): Association of the serotonin transporter gene whith sudden infant death syndrome: A haplotype analysis. Am J Med Genet 122, 238-245

Weese-Mayer DE, Ackerman MJ, Marazita ML, Berry-Kravis EM (2007): Research review sudden infant death syndrome: Review of implicated genetic factors. Am J Med Genet $\underline{143}, 771-788$

Wilken B, Lalley P, Bischoff AM, Christen HJ, Behnke J, Hanefeld F, Richter DW (1997): Treatment of apneustic respiratory disturbance with a serotonin-receptor agonist. J Pediatr 130, 89-94

Willinger M, James LS, Catz C (1991): Defining the sudden infant death syndrome (SIDS): deliberations of an expert panel convened by the National Institute of Child Health and Human Development. Pediatr Pathol 11, 677-684

Wright IK, Garratt JC, Marsden CA (1990): Effects of a selective 5-HT2 agonist, DOI, on 5-HT neuronal firing in the dorsal raphe nucleus and 5-HT release and metabolism in the frontal cortex. Br J Pharmacol British 99, 221-222 
Yamauchi M, Dostal J, Kimura H, Strohl KP (2008b): Effects of buspirone on posthypoxic ventilatory behaviour in the $\mathrm{C} 57 \mathrm{BL} / 6 \mathrm{~J}$ and $\mathrm{A} / \mathrm{J}$ mouse strains. $\mathrm{J} \mathrm{Appl}$ Physiol $\underline{105}, 518-526$

Yamauchi M, Ocak H, Dostal J, Jacono FJ, Loparo KA, Strohl KP (2008a): Post-sigh breathing behaviour and spontaneous pauses in the C57BL/6J (B6) mouse. Respir Physiol Neurobiol 162, 117-125 


\section{Danksagung}

Prof. Dr. med. M. Klintschar danke ich außerordentlich für seine engagierte Unterstützung und für die Überlassung des Themas meiner Promotionsarbeit.

Mein ganz besonderer Dank gilt Herrn Dr. rer. nat. Dr. med. T. Manzke für die Betreuung der Versuche, Hilfe und Zusammenarbeit.

Frau Dr. M. Krohn, Frau Anna-Maria Bischoff und Herrn Dr. M. Niebert danke ich für ihre Erklärungen zu verschiedenen laborexperimentellen Methoden. Herrn Dr. Schulz-Schäffer danke ich für die Bereitstellung zusätzlicher Proben. Für die organisatorische Unterstützung möchte ich Frau Thanhäuser sehr danken. 